\title{
Independent Technical Review of the Building 100 Plume, Former DOE Pinellas Site (Young - Rainey Star Center), Largo, Florida
}

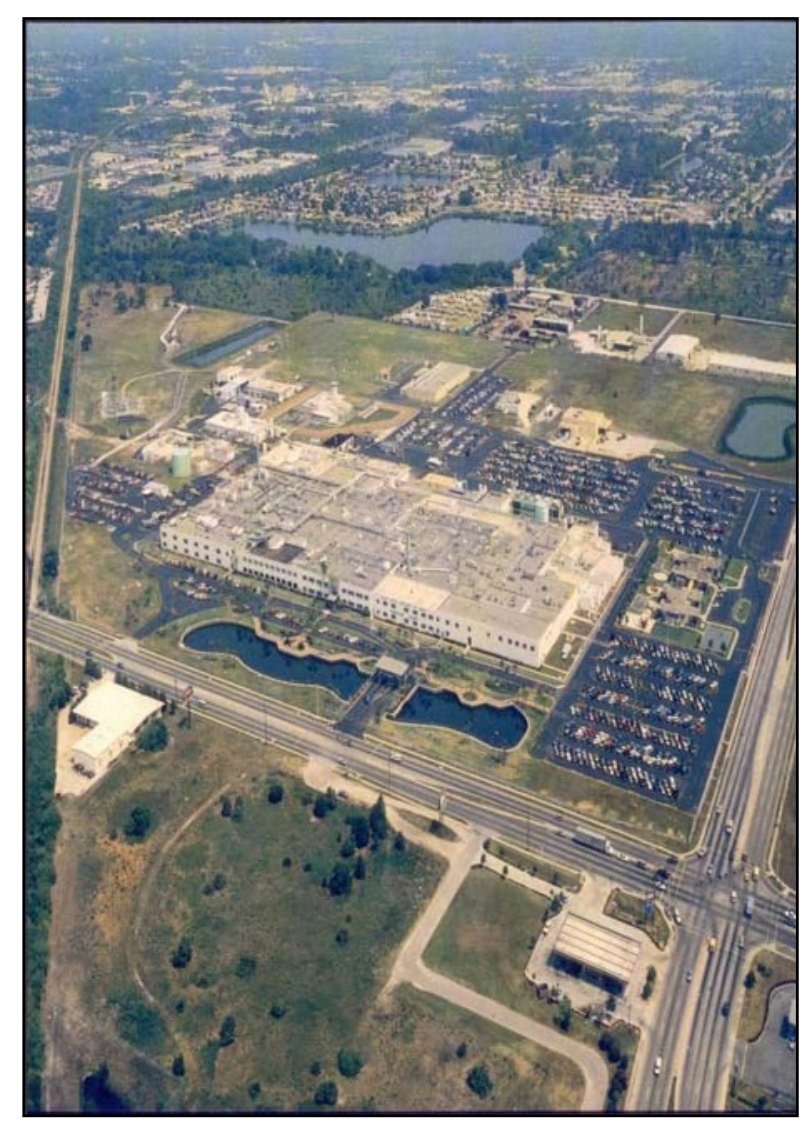

Prepared for: The U.S. Department of Energy Office of Environmental Management Groundwater and Soil Remediation Technology (EM32), Washington, DC

Prepared by: The DOE EM Center for Sustainable Groundwater and Soil Solutions, Savannah River National Laboratory, Aiken SC

June 2010

Technical content and coordination for this effort were provided by the Savannah River National Laboratory in conjunction with Contract No. DE-AC09-08SR22470 with the U.S. Department of Energy. 


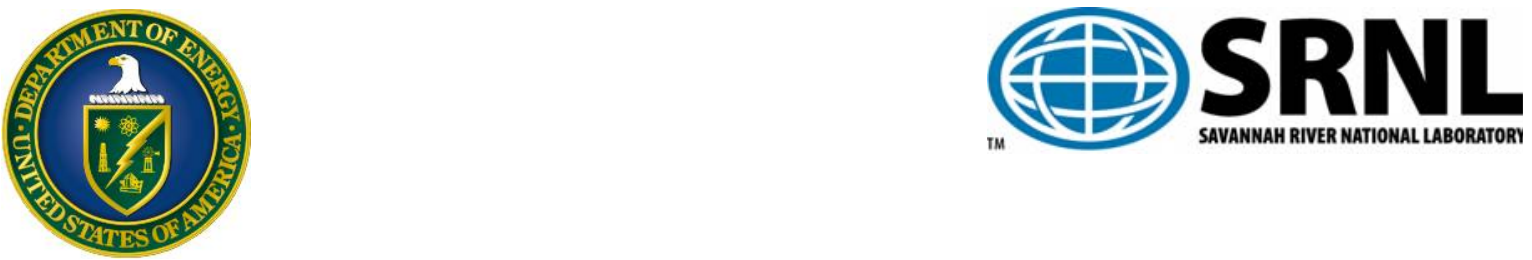

\section{Cover:}

Aerial photograph of the STAR Center, formerly DOE's Pinellas Plant, showing the location of Building 100.

\section{DISCLAIMER}

This work was prepared under an agreement with and funded by the U.S. Government. While the authors have taken care in the preparation of this report, neither the U. S. Government or its employees, nor any of its contractors, subcontractors or their employees, makes any express or implied: 1 . warranty or assumes any legal liability for the accuracy, completeness, or for the use or results of such use of any information, product, or process disclosed; or 2. representation that such use or results of such use would not infringe privately owned rights; or 3. endorsement or recommendation of any specifically identified commercial product, process, or service. Any views and opinions of authors expressed in this work do not necessarily state or reflect those of the United States Government, or its contractors, or subcontractors.

Printed in the United States of America

Prepared For

U.S. Department of Energy

Office of Engineering and Technology 


\title{
Independent Technical Review of the Building 100 Plume, Former DOE Pinellas Site (Young - Rainey Star Center), Largo, Florida
}

\author{
Authors: \\ Carol A. Eddy-Dilek ${ }^{1}$ \\ Joseph Rossabi ${ }^{2}$ \\ Mark Amidon ${ }^{1}$ \\ Dawn S. Kaback ${ }^{3}$ \\ Brian D. Riha ${ }^{1}$
}

Prepared for

Paul Beam

Department of Energy (DOE) Office of Groundwater and Soil

Remediation

Washington, D.C.

Jack Craig

Department of Energy (DOE) Office of Legacy Management

Pittsburgh, Pennsylvania

June 2010

\footnotetext{
${ }^{1}$ Savannah River National Laboratory, Aiken SC

${ }^{2}$ Redox Tech, LLC

${ }^{3}$ AMEC
} 


\section{Contents}

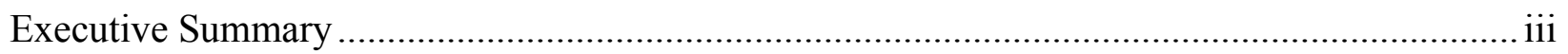

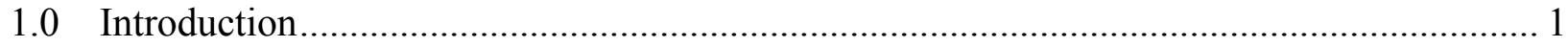

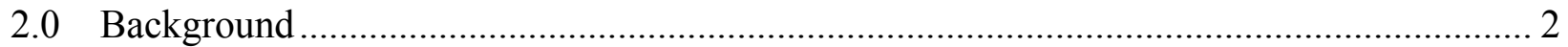

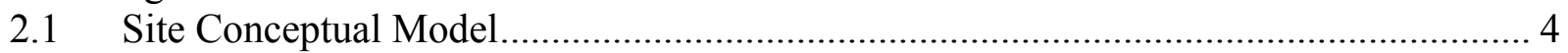

2.2 Nature and Extent of Contamination ……………................................................ 5

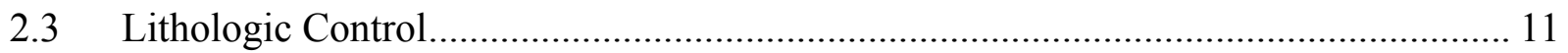

2.4 Evidence for Active Degradation.......................................................................... 15

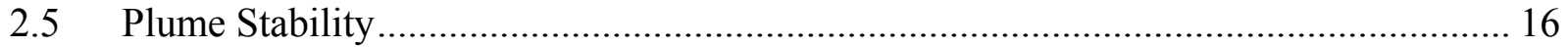

2.6 Evidence of Active Microbial Degradation ............................................................... 16

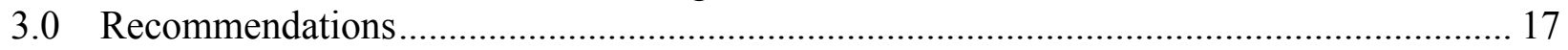

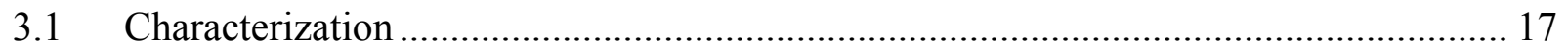

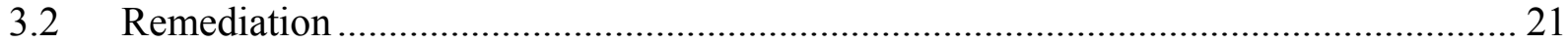

4.0 Implementation of Phased Dynamic Strategy.................................................................. 32

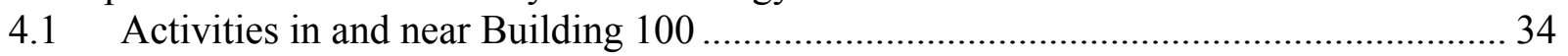

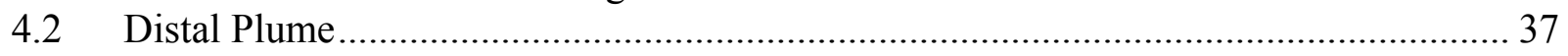

4.3 Recommended Decision Flow and Sequence of Activities ........................................... 38

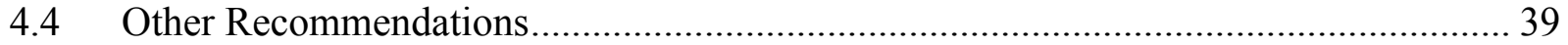

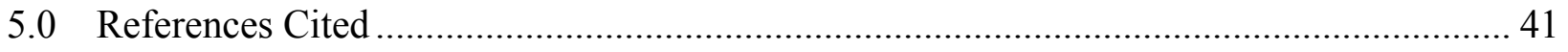

\section{Figures}

Figure 1. Location of Active SWMUs and the Building 100 Area at the STAR Center................. 3

Figure 2. Conceptual Model at Building 100 Area (modified from DOE, 2006)........................... 5

Figure 3. Well Locations and Grouping at Building 100, Pinellas Site............................................ 7

Figure 4. cVOC Time-Concentration Trends in Well S35B....................................................... 9

Figure 5. cVOC Time-Concentration Trends in Well S67C...................................................... 9

Figure 6. Geologic Cross Section at Building 100 ................................................................... 12

Figure 7. Geologic Cross Section at the Northeast Site................................................................ 13

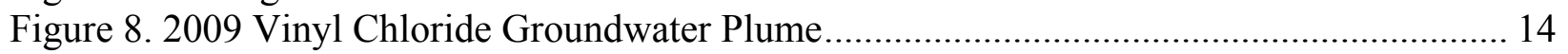

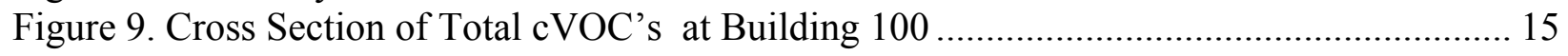

Figure 10. Pathway for Stepwise Reductive Dechlorination of Trichloroethene .......................... 16

Figure 11. Critical Chemical Species, Electron Acceptors, and Oxidation-Reduction Processes

Necessary for Reductive Dechlorination of TCE (dashed line)................................................... 17

Figure 12. Recommened location for ZVI Permeable Reactive Barrier....................................... 27

Figure 13. Proposed location of Treatment Line at the Site Boundary ........................................ 29

Figure 14. Location of source area sweep and below building treatment ...................................... 31

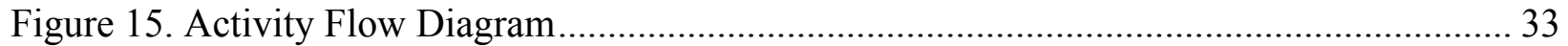

Figure 16. Proposed Locations for Passive Diffusion Samplers.................................................... 35

Figure 17. Location of Groundwater Samplers...................................................................... 36

Figure 18 Suggested sequencing for of remediation and characterization. .................................. 39 


\section{Tables}

Table 1. Effectiveness of Remediation Technologies at Building 100 ..................................... 3

Table 2. Minimum and Maximum Values for Well Data within Building 100, 1998-2009........ 8

Table 3. Characterization Matrix ......................................................................................... 19

Table 4. Geochemical Parameters for Reductive Dechlorination............................................ 22

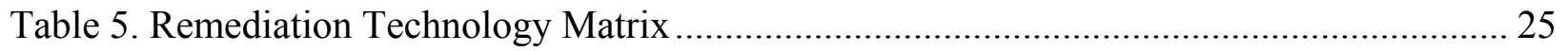




\section{Executive Summary}

Contaminated groundwater associated with Building 100 at the Young-Rainey Science, Technology, and Research Center, formerly the DOE Pinellas plant, is the primary remedial challenge that remains to be addressed at the site. Currently, Building 100 is an active industrial facility that is now owned and operated by the Pinellas county government. Groundwater samples collected from monitoring wells recently installed near the southern boundary of the site suggest that contaminated groundwater has migrated off the plant site. In response to the challenges presented by the Building 100 plume, the Office of Legacy Management (LM) requested assistance from the DOE Office of Groundwater and Soil Remediation (EM-32) to provide a review team to make technical recommendations so that they can efficiently and effectively address characterization and remediation of the plume. The review team was unanimous in the conclusion that a dynamic strategy that combines a phased implementation of direct push samplers, sensors, and tools can be used to better delineate the extent of contamination, control plume migration, and rapidly remediate the contaminated groundwater at the site.

The initial efforts of the team focused on reviewing the site history and data, organizing the information into a conceptual model, identifying appropriate technologies, and recommending an integrated strategy. The current groundwater data from the site indicate a two-lobed plume extending to the east and south. To the east vinyl chloride is the primary contaminant of concern, to the south, vinyl chloride and cis 1, 2-DCE are the primary contaminants. The limited data that are available suggest that reductive dechlorination of the TCE is already occurring but is not sufficient to prevent offsite migration of low concentrations of TCE daughter products. The team recommends that DOE pursue a strategy that builds on the natural cleansing capacity of the subsurface with reductive methods including biostimulation and/or bioaugmentation to provide a sustainable remediation system within the flow path of the plume. Additional data will be required to implement this approach and will include:

- Better delineation of the nature and extent of contamination

- Demonstration the plume is currently stable or shrinking

- Demonstration the full reductive dechlorination is occurring.

The technical team recommends that DOE use a phased approach to identify residual contamination and to provide rapid installation of remedies. Matrices of characterization and remediation sensors, technologies, and tools were developed by the team in order to match the specific conditions and requirements of the site. The team provides a specific example of remedy that includes the incorporation of a dynamic characterization strategy moving from minimally invasive to more aggressive field techniques, the consideration of multiple complementary remediation approaches based on a spatiotemporally phased approach keyed to the different demands of different parts of the plume, and the integration and sequencing of the characterization and remediation activities. 


\subsection{Introduction}

The U.S. Department of Energy (DOE) Office of Legacy Management (LM) requested assistance from the DOE Office of Environmental Management to provide an independent technical panel to review the current status of groundwater contamination associated with Building 100 at the Young - Rainey Science, Technology, and Research Center (STAR Center) located in Largo, Florida. The STAR Center was previously known as the Pinellas Plant, a former DOE site, that was constructed in the 1950s and used primarily to manufacture neutron generators for nuclear weapons. The former Pinellas Plant is now an industrial facility that is owned and operated by Pinellas County government. The property transfer agreement between DOE and Pinellas County requires DOE to investigate and remediate residual soil and groundwater contamination generated as a result of historical DOE operations.

Recent events related to construction of roadways adjacent to the site have resulted in identification of off-site groundwater contamination during installation of new monitoring wells at and beyond the boundary of the site. Groundwater samples collected from these wells contain volatile organic compounds at concentrations that exceed drinking water standards. Because of the high level of sensitivity to the presence of off-site groundwater contamination, LM requested that an independent team visit the site and review available data and information and provide technical recommendations that address characterization and remediation of the groundwater contamination associated with Building 100, both on and off of STAR Center property.

A group of technical experts attended a technical workshop at the STAR center from April 13 through 16, 2010. During the first day of the workshop, both contractor and DOE site personnel briefed the workshop participants. On subsequent days, the team reviewed baseline data and reports, received additional technical information from site personnel, evaluated work plans, determined critical issues and uncertainties, and recommended alternatives. This report documents the findings and recommendations of the independent technical review team.

The review team acknowledges and appreciates the support of the DOE and contractor personnel. We are grateful to both DOE (Jack Craig) and to the project personnel from the S.M. Stoller Corporation (Joe Daniel and Julian Caballero) for hosting the meeting and for their openness in providing access to the site data and reports. This high level and high quality of support was key to the success of the technical review. The authors appreciate the technical editing provided by Phyllis Price and David Foster that greatly improved the manuscript. 


\subsection{Background}

The Pinellas Plant was constructed by DOE in the mid-1950s primarily for the manufacture of neutron generators for nuclear weapons. Additional products manufactured at the site included radioisotope-powered thermoelectric generators, thermal batteries, specialty capacitors, crystal resonators, neutron detectors, lightning arrester connectors, and vacuum switch tubes. Operation of the plant ceased in 1995, and the property was sold in March 1995. DOE has continued to assess, monitor, and remediate residual contamination at the site through the present time.

The STAR Center has four active Solid Waste Management Units (SWMUs). Two of these SWMUs-PIN06 (the Old Drum Storage Site), and PIN12 (the Industrial Drain LeaksBuilding 100 Area),-will be remediated together and are referred informally as Building 100 Area. Figure 1 shows the locations of the active SWMUs and the Building 100 Area.

\section{History of Remediation}

At the 4.5-Acre Site, the Northeast Site, and Building 100, the contaminants of concern in groundwater include toluene and the chlorinated solvents trichloroethene (TCE), isomers of dichloroethene (DCE), methylene chloride, and vinyl chloride. Some of these solvents have also been found as non-aqueous-phase liquids (NAPLs) at the Northeast Site and the 4.5-Acre Site. At the Wastewater Neutralization Area (WWNA), the contaminant of concern in groundwater is arsenic. At Building 100, the contaminants of concern are TCE, methylene chloride, and vinyl chloride.

Since 1985, DOE has used a variety of techniques to address source and groundwater contaminant removal. At the 4.5-Acre Site, soil and drums were removed in 1985. Groundwater pump-and-treat remediation was performed from 1988 through 1997 and again in 2004 through 2005. Dual-phase extraction was implemented in 1997 and operated until 1999; biosparging began in 1999 and continued until 2003. Large-diameter augers were used for hot-spot excavation in 2009 with a follow-up action of bioinjection in 2010.

At the Northeast Site, soil and drums were removed in 1995. Groundwater pump-and-treat was performed from 1997 through 2003. In 2002, thermal treatment of subsurface NAPL contamination was tested on a small area of the site. Based upon positive test results, thermal treatment of subsurface NAPL contamination was implemented on a larger area of the site. Large-diameter augers were used for hot-spot excavation in 2009 with a follow-up action of bioenhancement by subsurface injection in 2010 .

At the WWNA, groundwater pump-and-treat was performed from 1997 through 2005. In 1999 contaminated soil was removed at the site.

At Building 100, groundwater pump-and-treat was performed from 1996 to 2006. The various techniques and their relative effectiveness are shown in Table 1. 
Table 1. Effectiveness of Remediation Technologies at Building 100

\begin{tabular}{|c|c|c|c|c|c|c|c|}
\hline \multirow[t]{2}{*}{ Technology } & \multicolumn{4}{|c|}{ Location } & \multicolumn{3}{|c|}{ Relative Effectiveness } \\
\hline & 4.5 Acre & Northeast & $\begin{array}{c}\text { WWN } \\
\text { A }\end{array}$ & $\begin{array}{c}\text { Building } \\
100\end{array}$ & Low & Medium & High \\
\hline Soil/Drum Removal & $\bullet$ & $\bullet$ & $\bullet$ & & & & - \\
\hline $\begin{array}{l}\text { Groundwater } \\
\text { Pump-and-Treat }\end{array}$ & $\bullet$ & $\bullet$ & $\bullet$ & $\bullet$ & $\bullet$ & & \\
\hline $\begin{array}{l}\text { Dual-Phase } \\
\text { Extraction }\end{array}$ & $\bullet$ & & & & $\bullet$ & & \\
\hline Biosparging & $\bullet$ & & & & $\bullet$ & & \\
\hline $\begin{array}{l}\text { Large-Diameter } \\
\text { Auger (LDA) }\end{array}$ & $\bullet$ & $\bullet$ & & & & & • \\
\hline Bioinjection & $\bullet$ & $\bullet$ & & & \multicolumn{3}{|c|}{ TBD } \\
\hline $\begin{array}{l}\text { Thermal } \\
\text { Treatment }\end{array}$ & & $\begin{array}{c}\bullet \\
\text { (Site A } \\
\text { and Site B) }\end{array}$ & & & & $\stackrel{\bullet}{\text { Site B }}$ & $\begin{array}{c}\bullet \\
\text { Site } \\
\text { A }\end{array}$ \\
\hline
\end{tabular}

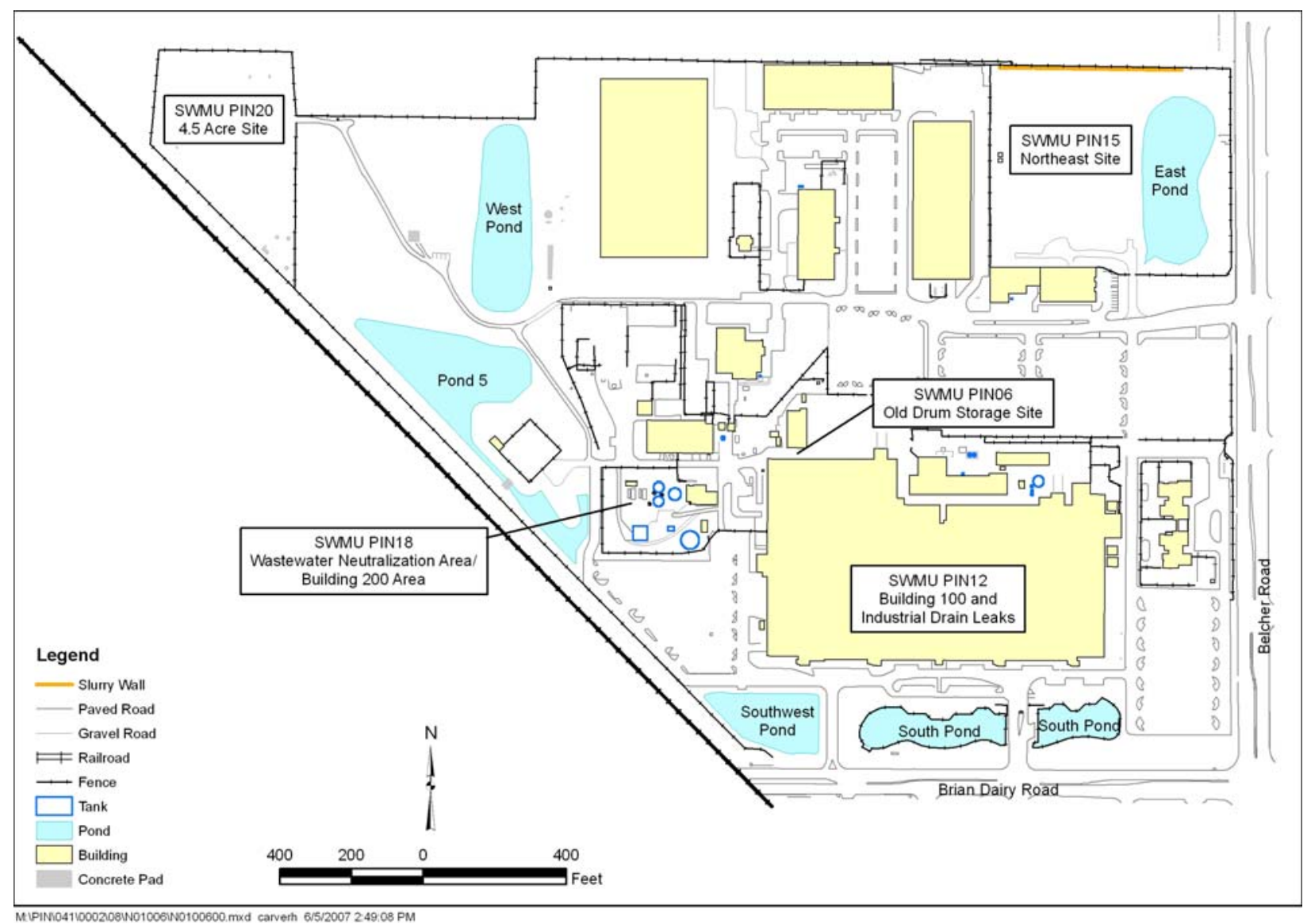

Figure 1. Location of Active SWMUs and the Building 100 Area at the STAR Center 


\subsection{Site Conceptual Model}

Conceptually, the contaminant hydrology at the Building 100 Area is relatively straightforward. Liquid effluents were released from two sources, a storage pad located northwest of the building and through leaks in various drain lines under the building (Figure 2). The primary contaminant of concern at the Building 100 Area is TCE, an industrial solvent that is considered a dense nonaqueous-phase liquid (DNAPL) because of its limited aqueous solubility and density greater than that of water. Contamination from the primary sources penetrated into the undifferentiated shallow surficial aquifer, which consists of layers of sediments of variable continuity and permeability. Initially, the contamination moved both vertically and laterally away from the source areas in both separate and dissolved phases until it reached the underlying limestone confining unit (Hawthorn Formation). The migration of separate-phase DNAPL probably created secondary source zones within the shallow layered sediments where "pools" of DNAPL would accumulate within stratigraphic low spots. The presence of localized DNAPL within the shallow groundwater sediments would provide for a continual source of dilute organic contamination to the groundwater system. The surficial aquifer is approximately $30-35$ feet (ft) thick, and depth to water ranges from 3 to $5 \mathrm{ft}$ below land surface. Historical groundwater flow rate is estimated to be between 17 to $22 \mathrm{ft} /$ year with a flow direction south and east from the building (DOE 2008b). 


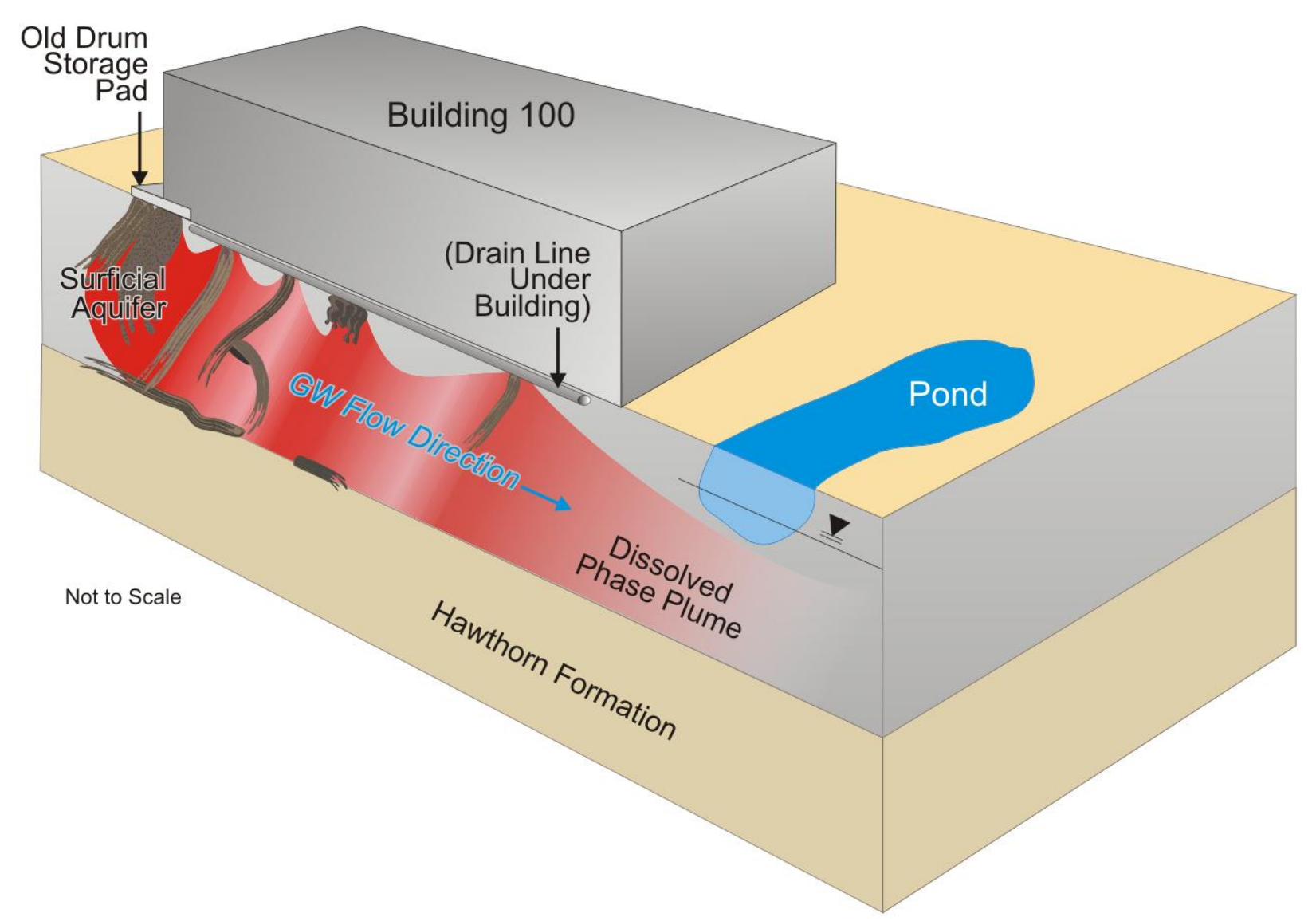

Figure 2. Conceptual Model at Building 100 Area (modified from DOE, 2006)

The groundwater data used in this evaluation were extracted from the Geospatial Environmental Mapping System (GEMS) at the LM website

(http://gems.lm.doe.gov/imf/img.jsp?site=pinellascounty\&title=Pinellas County, FL, Site). The data set consisted of posted data from the years from 1998 to 2009.

\subsection{Nature and Extent of Contamination}

Groundwater contamination is present within the undifferentiated shallow surficial aquifer. This aquifer overlies the Hawthorn Formation. The Hawthorn Formation consists of sand, clay, limestone, and dolomite, and forms a dividing layer between the surficial aquifer and the underlying regional Floridan aquifer. Aquifer tests indicate that is very unlikely that contamination in the surficial aquifer will migrate through the Hawthorn Formation and affect the underlying Floridan aquifer (DOE, 2006).

The surficial aquifer is typical of coastal plain geology and consists of alternating beds of sands, silts, and clays with interbedded clastic material (e.g., carbonate, shells). These alternating beds vary in thickness and exhibit various permeabilities, which control the lateral and vertical movement of groundwater and influence contaminant transport. In addition, three ponds located near Building 100 also impact local hydrology and contaminant transport, as these ponds receive storm water runoff and are in direct communication with the shallow surficial aquifer. 


\section{Building 100 Area}

To better understand the potential impact to soils beneath Building 100, soil samples were collected from the unsaturated sediments beneath vacant areas of the building. Analytical results of the sampling detected no cVOCs above U.S. Environmental Protection Agency (EPA) soil screening levels (DOE, 2006). Groundwater monitoring wells were also installed during this time period to provide long-term monitoring of groundwater impact and contaminant transport.

Even though no cVOCs were detected above the EPA screening levels, it was assumed that TCE could be present. However, no historical records are available to quantify the volume of TCE used or the duration of the leaks that released the solvent into the subsurface. Therefore, because of a lack of investigative data and information about historical operations, it is unknown if DNAPL is present within the saturated sediments.

To assess the extent of groundwater contamination, wells located within Building 100 were grouped into three main areas (Figure 3): northwest, southwest, and east central. The wells were further grouped according to well construction and completions depths within the undifferentiated shallow surficial aquifer.

Groundwater wells within Building 100 have been sampled to monitor and assess groundwater quality as a result of past releases and to determine impact to groundwater and downgradient receptors. Previous groundwater data may have indicated that DNAPL was present, based on the solubility of TCE, but no characterization or historical data are available to quantify the amount or location. Historical data indicate that TCE concentrations in groundwater are highest in the northwest corner of the building, where concentrations are at or near DNAPL solubility. Along with the high concentrations of TCE, cis-1, 2-DCE and vinyl chloride are also present in elevated concentrations in this area. In contrast, groundwater data for the east central part of Building 100, downgradient of the northwest corner of the building, indicate no presence of TCE. However, vinyl chloride is the principal cVOC, and cis-1, 2-DCE is present in lower concentrations. The data from both areas of the building provide strong evidence that TCE is degrading anaerobically. This interpretation is further substantiated by low dissolved oxygen values and negative oxidation-reduction potentials.

No groundwater contamination has been detected in the Floridan aquifer, which underlies the Hawthorn aquitard at Building 100.

Table 2 depicts the minimum and maximum data values for the wells located within the three main areas of Building 100. The most recent sampling events (late 2009 and early 2010) were not available on the LM website but were provided in hard copy for the team to use. However, those data were not incorporated into this table.

As shown on Table 2, TCE concentrations are greater in the northwest corner of Building 100. Significant concentrations of the degradation products cis-1, 2-DCE and vinyl chloride are also present in groundwater of this same area due to reductive dechlorination. Data in the east central part of Building 100 indicate no presence of TCE but still indicate the presence of cis-1, 2-DCE and vinyl chloride, although in lower concentrations. In both areas of the building, the concentrations of all the cVOCs are declining as a result of reductive dechlorination. 


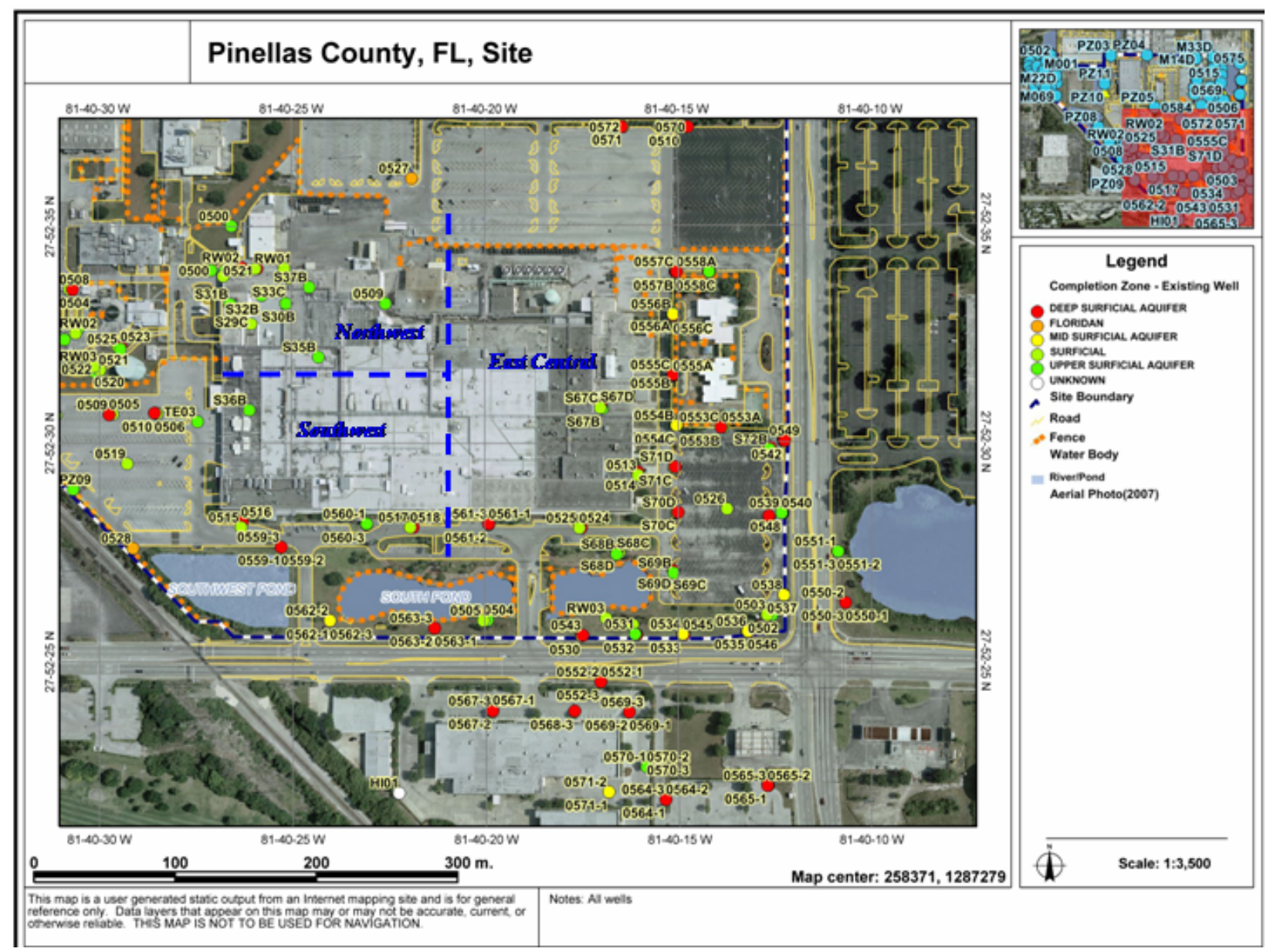

Figure 3. Well Locations and Grouping at Building 100, Pinellas Site 
Table 2. Minimum and Maximum Values for Well Data within Building 100, 1998-2009

\begin{tabular}{|c|c|c|c|c|c|c|c|c|c|c|}
\hline \multirow{2}{*}{ Analyte } & & \multicolumn{3}{|c|}{ East Central } & \multirow{2}{*}{ Well(s) } & \multicolumn{2}{|c|}{ Northwest } & \multirow{2}{*}{ Well(s) } & \multirow{2}{*}{\begin{tabular}{|c|} 
Southwest \\
US \\
\end{tabular}} & \multirow{2}{*}{ Well } \\
\hline & & DS $^{\mathbf{a}}$ & $\mathbf{S F}^{\mathbf{b}}$ & $\mathbf{U S}^{\mathrm{c}}$ & & SF & US & & & \\
\hline \multirow{2}{*}{$\begin{array}{c}\text { cis-1,2- } \\
\text { DCE }\end{array}$} & $\begin{array}{c}\text { Minimum } \\
\text { Value } \\
(\mu \mathrm{g} / \mathrm{L})^{\mathrm{d}}\end{array}$ & 22 & 69 & 19 & \multirow{2}{*}{$\begin{array}{l}\text { S67D } \\
\text { S67C } \\
\text { S67B }\end{array}$} & 0.23 & 0.36 & \multirow{2}{*}{$\begin{array}{l}\text { S29C } \\
\text { S30B } \\
\text { S31B } \\
\text { S32B } \\
\text { S33C } \\
\text { S35B } \\
\text { S37B } \\
\end{array}$} & 0.16 & \multirow{2}{*}{ S36B } \\
\hline & $\begin{array}{c}\text { Maximum } \\
\text { Value } \\
(\mu g / L)\end{array}$ & 210 & 720 & 51 & & 5700 & 110000 & & 1.1 & \\
\hline \multirow{2}{*}{ TCE } & $\begin{array}{c}\text { Minimum } \\
\text { Value } \\
(\mu \mathrm{g} / \mathrm{L})\end{array}$ & 0.13 & 0 & 0 & \multirow{2}{*}{$\begin{array}{l}\text { S67D } \\
\text { S67C } \\
\text { S67B }\end{array}$} & 1.8 & 0.27 & \multirow{2}{*}{$\begin{array}{l}\text { S29C } \\
\text { S30B } \\
\text { S31B } \\
\text { S32B } \\
\text { S33C } \\
\text { S35B } \\
\text { S37B }\end{array}$} & 0.1 & \multirow{2}{*}{ S36B } \\
\hline & $\begin{array}{c}\text { Maximum } \\
\text { Value } \\
(\mu g / L)\end{array}$ & 0.26 & 0 & 0 & & 3800 & 68000 & & 0.14 & \\
\hline \multirow{2}{*}{$\begin{array}{c}\text { Vinyl } \\
\text { Chloride }\end{array}$} & $\begin{array}{c}\text { Minimum } \\
\text { Value } \\
(\mu g / L)\end{array}$ & 28 & 95.2 & 2.88 & \multirow{2}{*}{$\begin{array}{l}\text { S67D } \\
\text { S67C } \\
\text { S67B }\end{array}$} & 0.76 & 0.93 & \multirow{2}{*}{$\begin{array}{l}\text { S29C } \\
\text { S30B } \\
\text { S31B } \\
\text { S32B } \\
\text { S33C } \\
\text { S35B } \\
\text { S37B }\end{array}$} & 0.76 & \multirow{2}{*}{ S36B } \\
\hline & $\begin{array}{c}\text { Maximum } \\
\text { Value } \\
(\mu g / L)\end{array}$ & 126 & 550 & 660 & & 3300 & 20000 & & 2.2 & \\
\hline
\end{tabular}

${ }^{\mathrm{a} D S}$ : Deep Surficial Aquifer

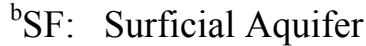

${ }^{c} U S$ : Upper Surficial Aquifer

${ }^{\mathrm{d}} \mu \mathrm{g} / \mathrm{L}$ : micrograms per liter

Source: Legacy Management GEMS website database

(http://gems.lm.doe.gov/imf/img.jsp?site=pinellascounty\&title=Pinellas County, FL, Site)

Well S35B was selected to best demonstrate the reductive dechlorination of TCE. This well is located in the northwest corner of Building 100 and has historically exhibited high TCE concentrations (maximum value of 68,000 micrograms per liter $[\mu \mathrm{g} / \mathrm{L}]$ in 1999) and high concentrations of the degradation products cis-1, 2-DCE and vinyl chloride. During this same time frame, the maximum concentration of cis-1,2-DCE in this well was $80,000 \mu \mathrm{g} / \mathrm{L}$, but 3 years later (in 2002) the highest detected concentration was $110,000 \mu \mathrm{g} / \mathrm{L}$. Similarly, the maximum concentration of vinyl chloride detected in well S35B during 1999 was $8200 \mu \mathrm{g} / \mathrm{L}$, but in 2003 the highest concentration was $20,000 \mu \mathrm{g} / \mathrm{L}$. TCE groundwater concentrations in 2009 in the northwest corner of Building 100 are an order of magnitude lower than the maximum concentration detected in 1999.

Since May 2003, concentrations of TCE and its degradation products cis-1, 2-DCE and vinyl chloride in well S35B have decreased steadily, as shown in Figure 4. This trend supports the interpretation that anaerobic (reductive) degradation is ongoing, as also supported by low dissolved oxygen values and negative oxidation-reduction potentials. Data from well S67C show 
additional evidence of anaerobic degradation. This well is located downgradient in the groundwater plume but still under Building 100. Groundwater data from this well show no detections of TCE, but cis-1, 2-DCE and vinyl chloride are present with decreasing trends (Figure 5). Data from these wells indicate that reductive dechlorination is very active with significant reduction of high TCE concentrations, increased concentrations of degradation products, and overall decreasing trends of cVOCs.

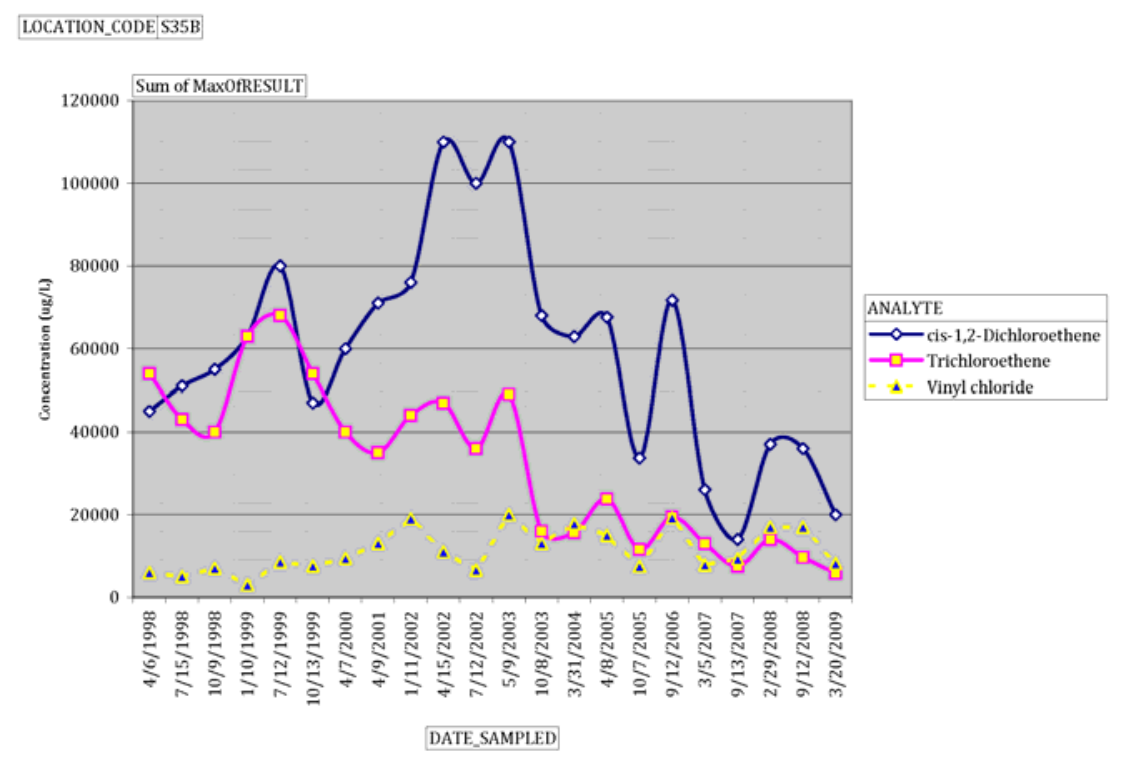

Figure 4. cVOC Time-Concentration Trends in Well S35B

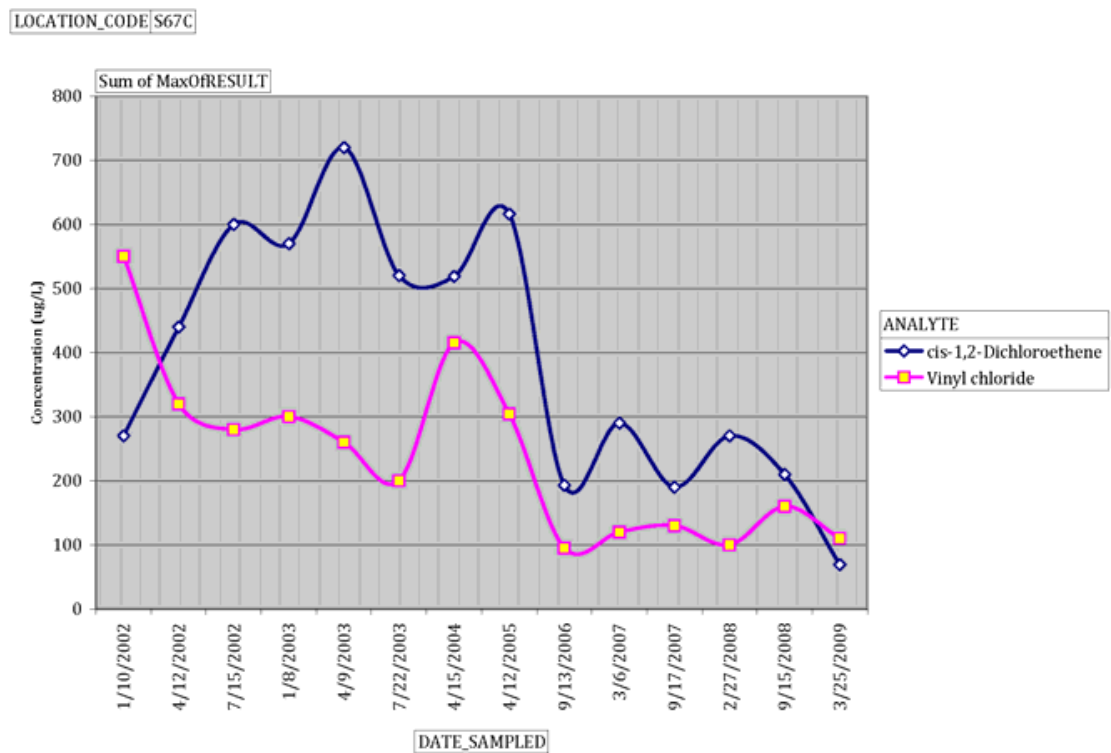

Figure 5. cVOC Time-Concentration Trends in Well S67C 


\section{Distal Plume}

Current groundwater plume maps indicate a two-lobe plume in the shallow surface aquifer with one lobe extending to the east and the other extending to the south of Building 100. The divergence of this groundwater plume is not fully understood. Possible explanations include different lithology between the lobes, prior construction activities that may have pulled the plume in a different direction, preferential groundwater flow paths to the east and south, additional contaminant source material, hydrology associated with the ponds, and/or the previous bioremediation pilot test that was conducted on the eastern side of Building 100. . But in any event, groundwater contamination is present and at further reaches to the south than the east; which indicates an overall flow direction.

From Building 100 to the south, vinyl chloride and cis-1, 2-DCE are the primary groundwater contaminants; TCE is not present in the distal portions of the groundwater plume. As reductive dechlorination continues, cis-1, 2-DCE concentrations decrease. To the east, vinyl chloride is the primary cVOC, which indicates that the intermediate byproduct (cis-1, 2-DCE) has degraded and is no longer prevalent. Also, it is interesting to note that, at a distance from the building, cVOC contaminant concentrations at a given location within the shallow surficial aquifer are generally higher at depth indicating a downward vertical flow component to contaminant transport, which may be controlled by subsurface soil heterogeneity.

Until recently, the extent of groundwater contamination was thought to be within the old boundary of the Pinellas site. It was not until a continuous multichannel tubing (CMT) well was installed along Dairy Farm Road to the south of Building 100 that elevated levels of vinyl chloride indicated that the groundwater plume might be migrating off site. TCE is not present at this well, and lower concentrations of cis-1, 2-DCE are detected with increasing distance from the building. Additional downgradient CMT wells were installed in the adjacent Better Business Forms property to address the concern that the groundwater plume may be migrating farther off site and to determine the extent of the plume.

Data from the newly installed CMT wells indicate that vinyl chloride concentrations decrease farther along the southern extent of the groundwater plume. However, data from well 0569 indicate a localized area of higher concentrations of vinyl chloride north of the Better Business Forms property, along the boundary between the old Exxon site and Harrod Properties. No vinyl chloride is detected at sampling locations south and east of this well. Upgradient of well 0569 , vinyl chloride concentrations are about 20 percent of the concentrations detected at the new well. Since there are no long-term data, no conclusion can be drawn from this one sampling event. Further sampling and monitoring should be conducted to determine the trend of the vinyl chloride and assess any further investigation that may be warranted.

Limited data are available to assess whether full reductive dechlorination is occurring. The end products of reductive dechlorination of TCE are ethene and ethane. Trace concentrations of these end products, ethane and ethene, have been detected in some samples, providing some indication that full reductive dechlorination is occurring. Additional data are needed to fully assess the presence of these end products and to provide further evidence that full reductive dechlorination is occurring.

Groundwater contamination has never been detected in the Floridan aquifer, which lies beneath the Hawthorn aquitard. 
Overall, the extent of the groundwater plume south and east of Building 100 is not fully understood. Currently, a plan is being developed to collect additional groundwater data to evaluate the extent of groundwater contamination.

\subsection{Lithologic Control}

As described in Section 2.2, the geology in the undifferentiated shallow surficial aquifer at the Pinellas site consists of silty-to-shelly, fine-grained sands. The surficial aquifer at the Building 100 Area ranges in thickness from approximately 35 to $40 \mathrm{ft}$. The surficial sediments and underlying Hawthorn Formation are shown on the cross section in Figure 6 (DOE, 2006). The surficial aquifer matrix is mostly sand, but layers of shelly sand and silty sand are also present, indicating significant subsurface heterogeneity and the potential presence of preferential flow paths, as shown in Figure 7 (DOE, 2008a)..

The two-lobe groundwater plume provides further evidence of subsurface heterogeneity, as depicted in Figure 8 (Stoller, 2010). Varying permeabilities of subsurface sediments can control groundwater flow and contaminant transport. Previous reports have estimated the hydraulic conductivity of the surficial aquifer to be approximately $1 \mathrm{ft} /$ day with an estimated effective porosity of 0.30 (DOE, 2009), which yields a groundwater flow rate of 2-3 ft/yr at Building 100 . This slow groundwater flow rate allows for additional contaminant residence time in the groundwater and limits the expanse of the groundwater plume.

In addition to the varying lithology, groundwater contaminant distribution also appears to stratify (Figure 9) (DOE, 2006). Concentrations of breakdown products tend to be higher at depth in the shallow aquifer. In some cases, contaminant concentrations in the upper portion of the surficial portion are low or even not detected, and higher concentrations are detected at greater depths. 


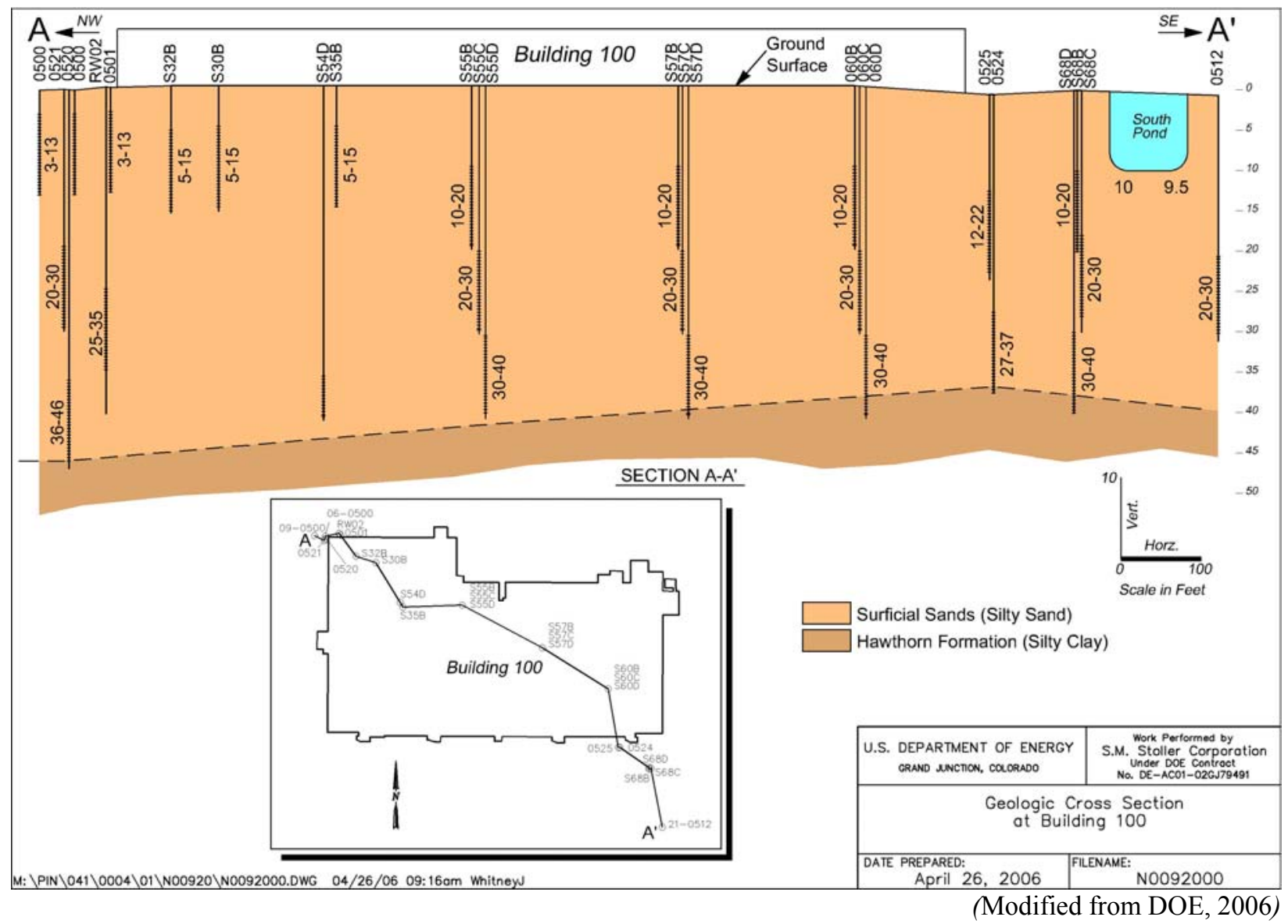

Figure 6. Geologic Cross Section at Building 100 


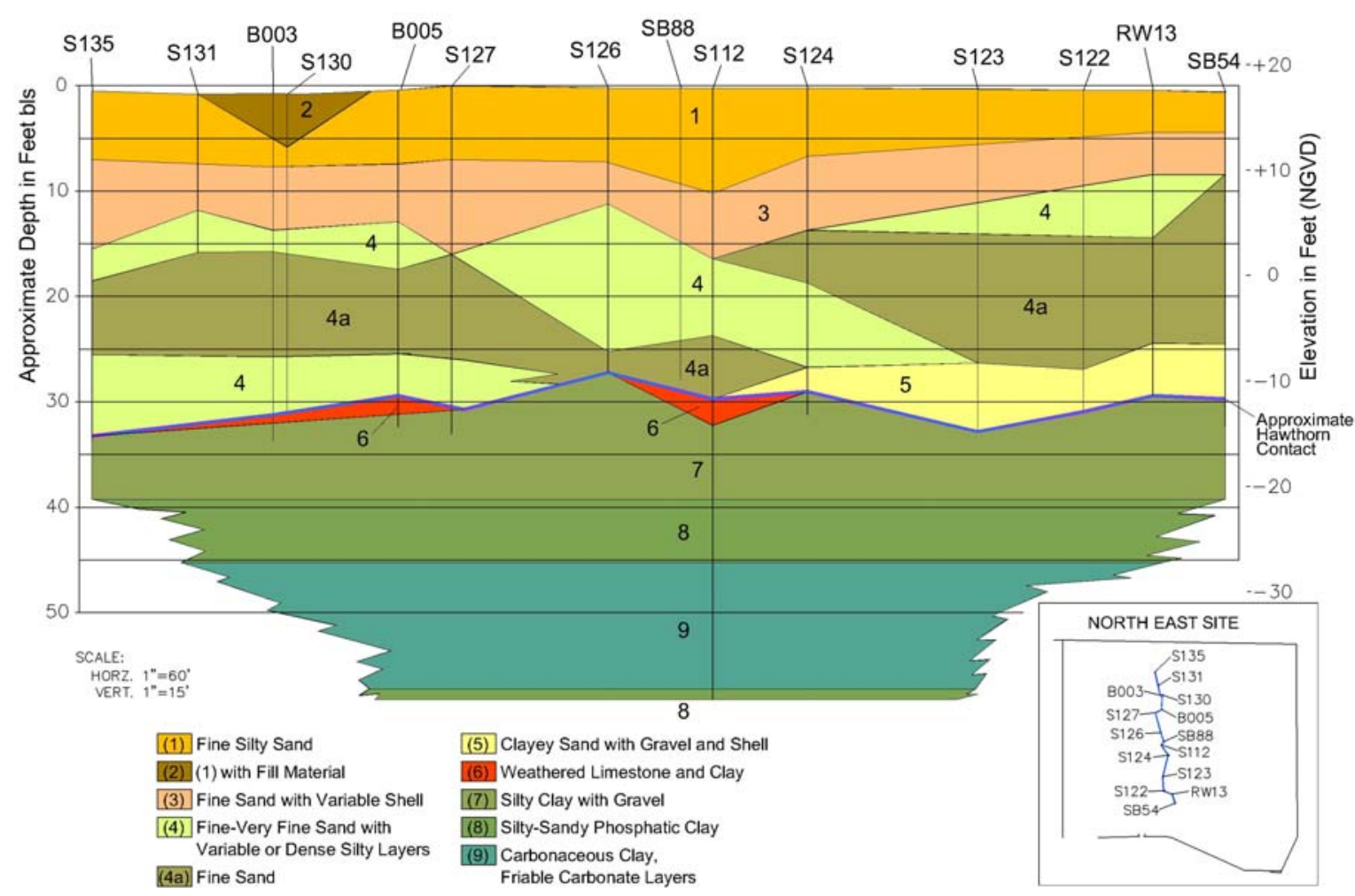

Figure 7. Geologic Cross Section at the Northeast Site 


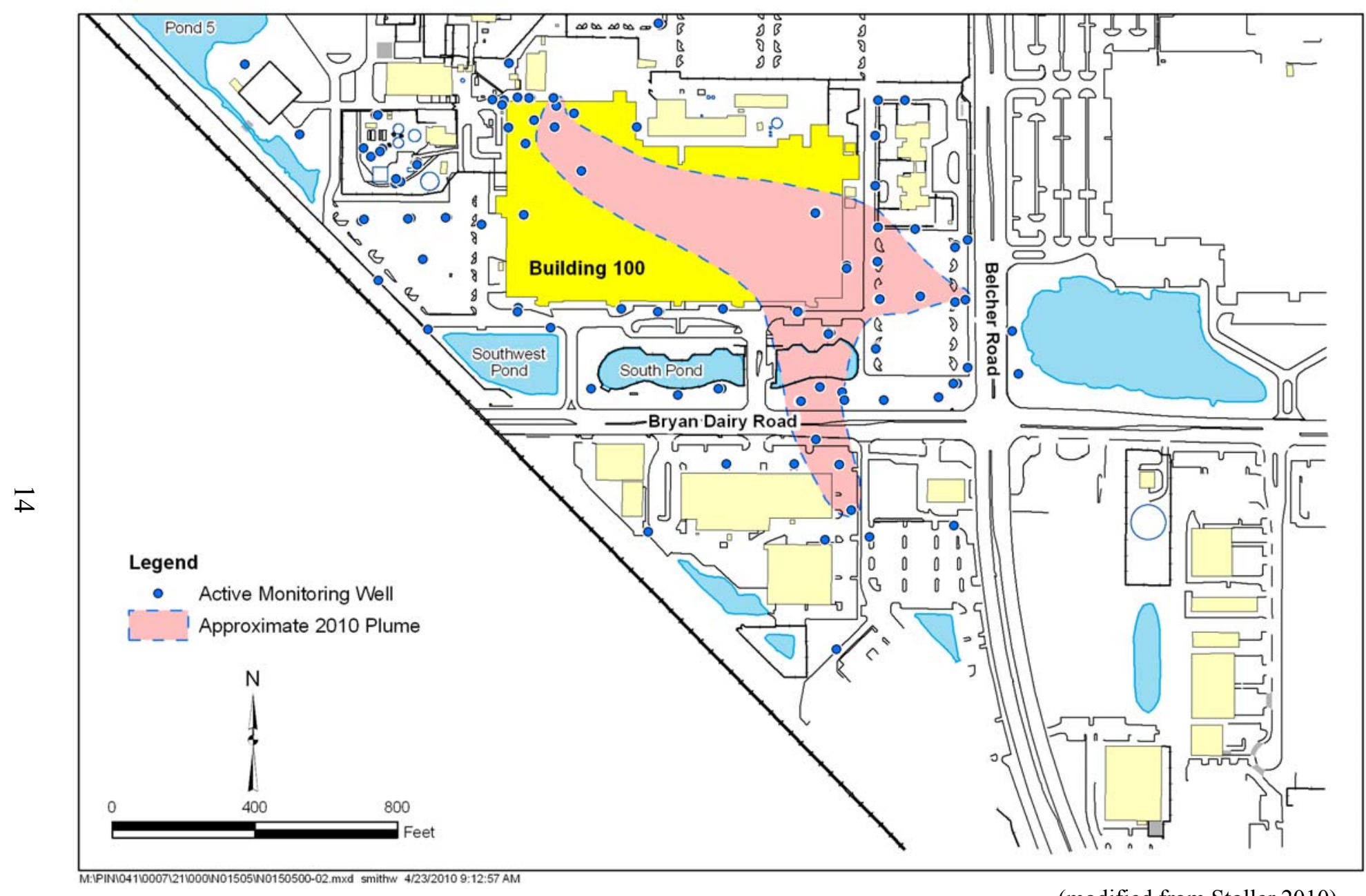

(modified from Stoller,2010)

Figure 8. 2009 Vinyl Chloride Groundwater Plume 


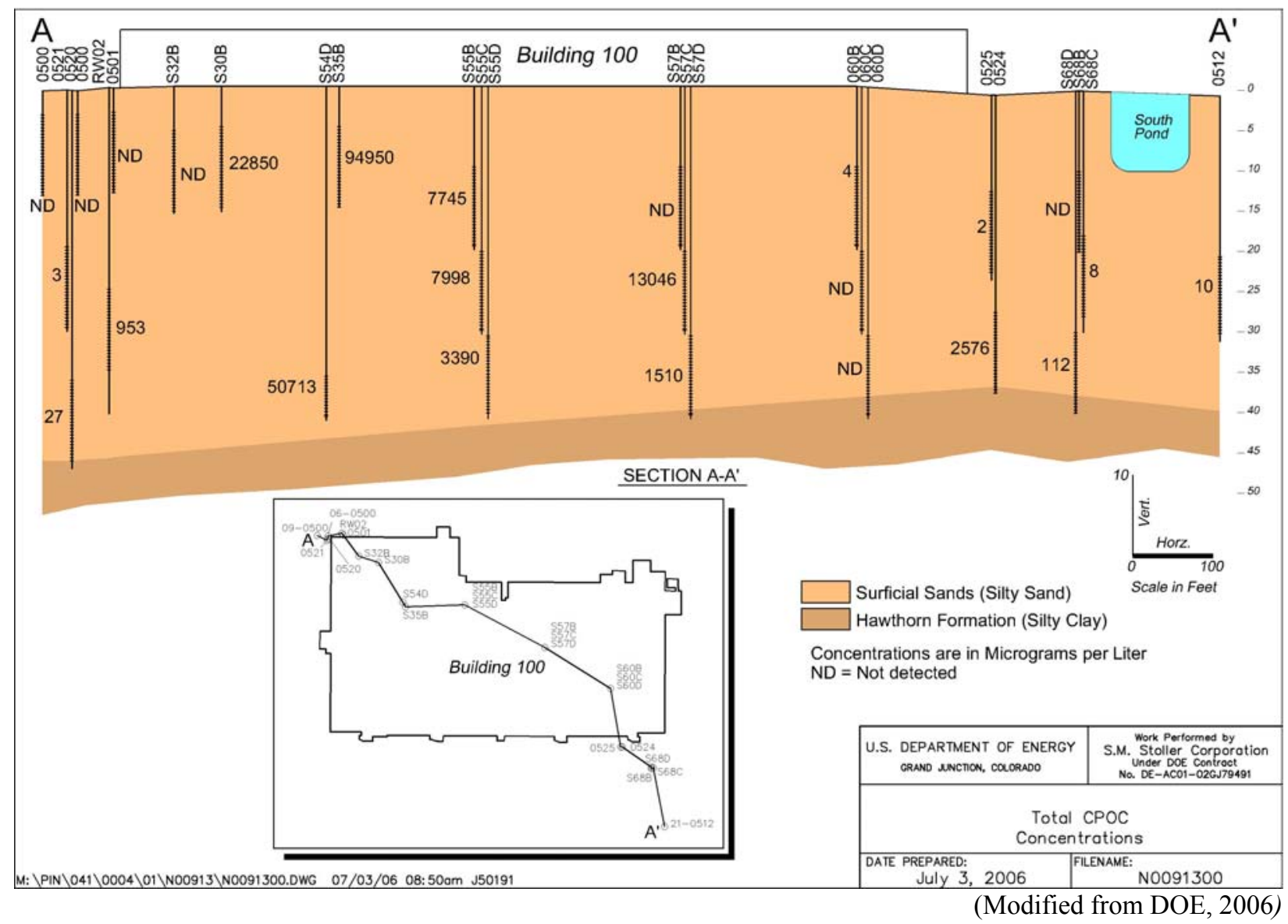

Figure 9. Cross Section of Total cVOC's at Building 100

\subsection{Evidence for Active Degradation}

As described in previous sections, the subsurface lithology in the vicinity of Building 100 varies and generally has a low permeability. This varying lithology and low permeability result in slow groundwater flow from the site and a relatively long residence time of the contaminants in the groundwater. This increased residence time allows sufficient time for anaerobic degradation of the cVOCs to occur, thereby reducing the mass flux from the sources to the groundwater and within the groundwater itself. This is demonstrated by the significant reduction in TCE (parent product) concentrations in the northwest corner of Building 100 and increased concentration of degradation products such as cis-1,2-DCE and vinyl chloride at the source. Farther downgradient, TCE is no longer detected, and cis-1,2-DCE and vinyl chloride concentrations also are decreasing.

This overall process limits the size and extent of the groundwater plume. Considering the operational time at the Pinellas site and the mass of contaminants present in the groundwater, the groundwater plume could have been much larger and expansive, as identified at other DOE sites (e.g., M Area groundwater plume at the Savannah River Site). But slow groundwater flow and anaerobic degradation have reduced groundwater contaminant concentrations and have limited the expanse of the groundwater plume to a narrow two-lobe area. 


\subsection{Plume Stability}

The stability of the Building 100 plume has not been fully evaluated. Previous data have indicated that the plume was relatively stable in size and that concentrations were decreasing (DOE, 2009). Additional characterization and monitoring conducted recently south of Building 100 and off site indicate that the plume is located south of the originally delineated plume. However, since previous data in this southern area are not available, the stability of the plume cannot be evaluated. Based on groundwater contour lines and current plume shape, the source is emanating both to the east and south of Building 100 . The groundwater gradients are likely controlled by the size and shape of the building (runoff) and possibly by unknown geologic features. These uncertainties may warrant a formal evaluation of plume stability following EPA protocols.

\subsection{Evidence of Active Microbial Degradation}

Anaerobic bioremediation is a proven technology in which anaerobic microorganisms degrade chlorinated solvents by the mechanism of reductive dehalogenation (Figure 10). The pathway for this mechanism includes the degradation intermediates DCE, vinyl chloride, and ethene. Data from groundwater wells at the site indicate that these degradation products are present. This microbial activity requires strongly anaerobic conditions and the presence of anaerobic microorganisms possessing reductive dehalogenation capability. In cases where natural conditions do not support active anaerobic reductive dehalogenation, it is common to deploy biostimulation (addition of carbon sources to produce reducing conditions) as well as bioaugmentation (addition of anaerobic halorespiring bacteria) to achieve in situ anaerobic biodegradation of chlorinated solvents. Correct conditions and the presence of appropriate biocatalysts will commonly result in complete degradation of chlorinated solvents.

\section{Reductive Dechlorination of TCE}

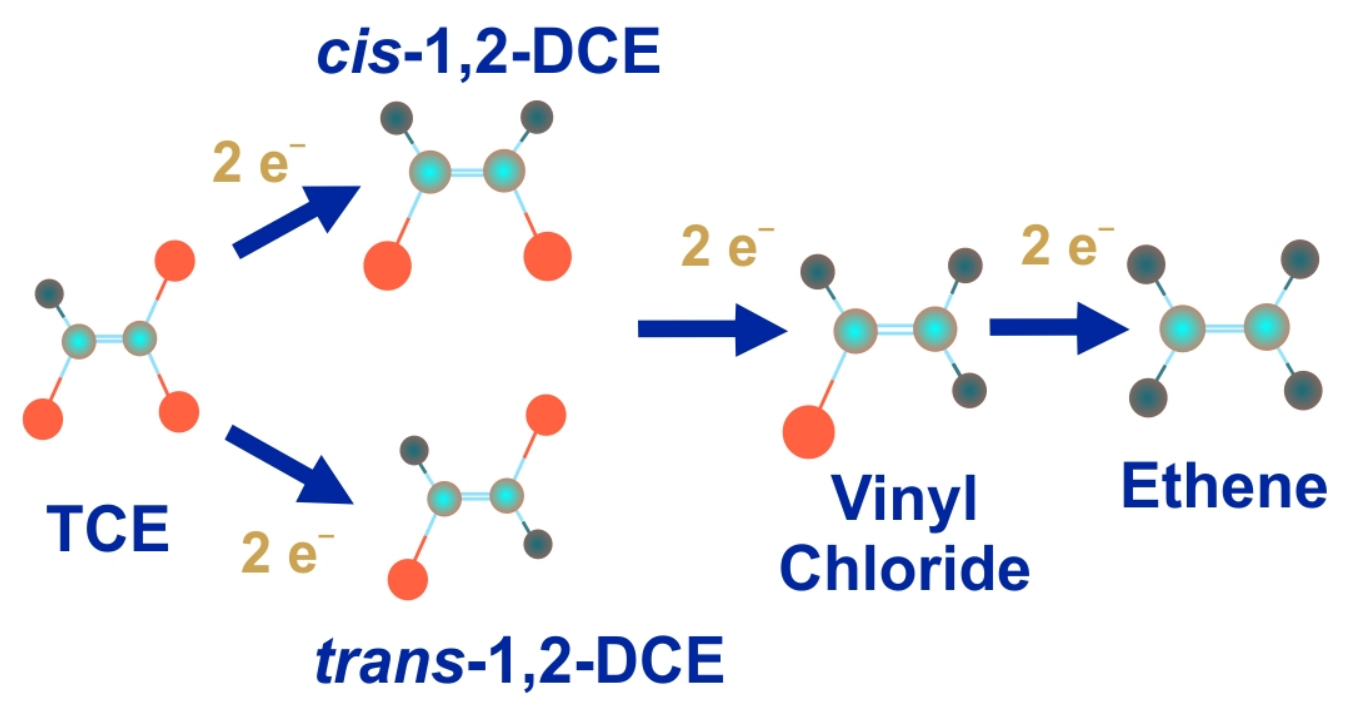

Figure 10. Pathway for Stepwise Reductive Dechlorination of Trichloroethene 
Because halorespiring bacteria can use chlorinated ethenes as terminal electron acceptors to gain energy, the environment should first be substantially depleted of all other potential terminal electron acceptors with higher energy levels, such as nitrate and sulfate (Figure 11). The halorespirer Dehalococcoides ethenogenes is one of the few organisms that degrade TCE all the way to ethene, via stepwise reductive dechlorination. However, some sites are known to go into what is referred to as a "stall," in which reductive dechlorination stops at either cis-DCE or vinyl chloride. Usually this stall is caused by lack of halorespirers or high concentrations of competing terminal electron acceptors. Additionally, the bioprocess conditions need to be held within acceptable ranges of $\mathrm{pH}$. Macronutrient additions (primarily nitrogen and phosphorous) may also be required. For in situ biostimulation at the Building 100 Area, the greatest problem will be the high concentrations of sulfate and low concentrations of macronutrients, and possibly the low concentrations of electron donors, as indicated by the lower concentrations of organic carbon in the groundwater. Further characterization may suggest that biostimulation is necessary with electron donors.

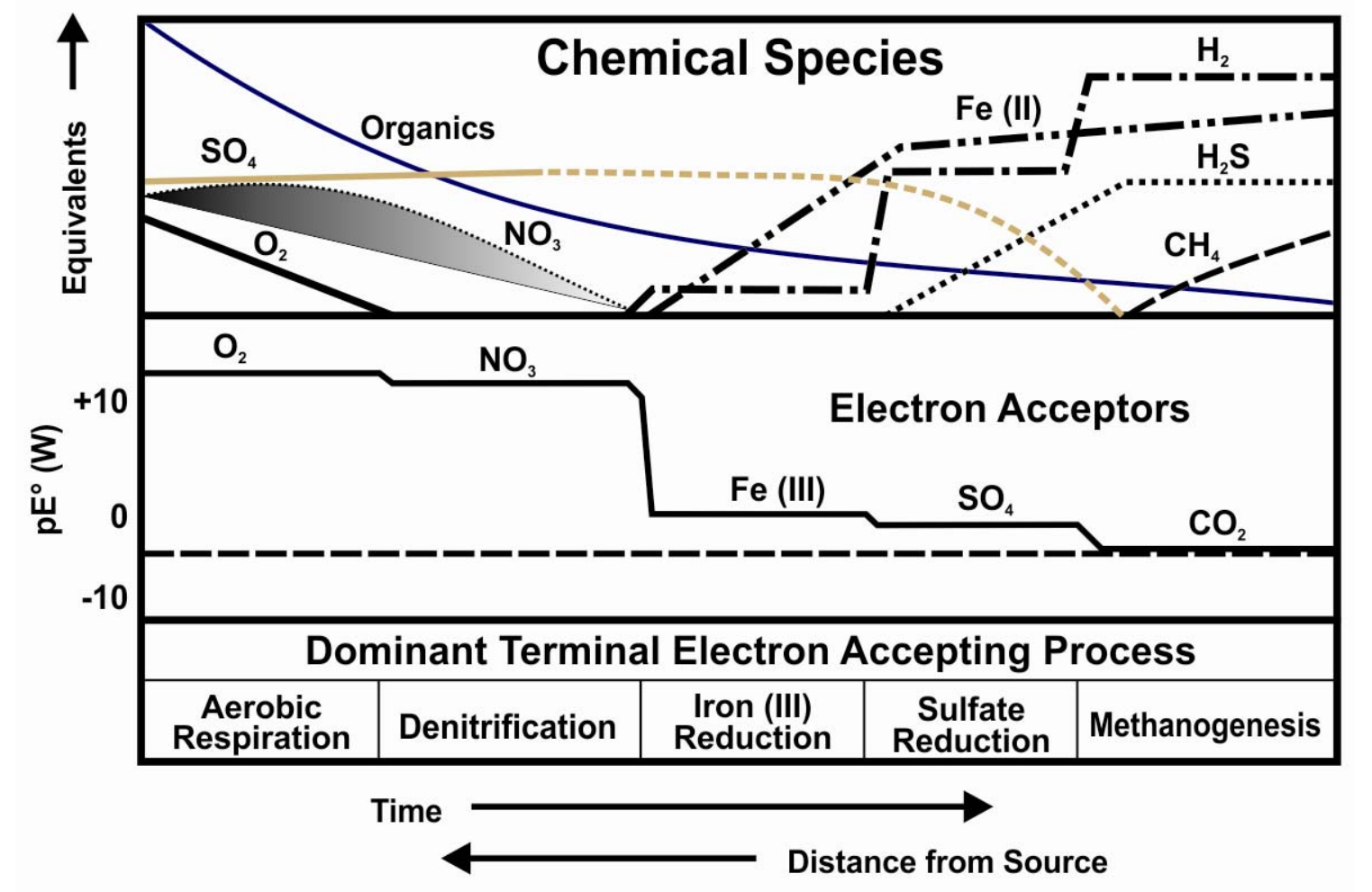

Figure 11. Critical Chemical Species, Electron Acceptors, and Oxidation-Reduction Processes Necessary for Reductive Dechlorination of TCE (dashed line)

\subsection{Recommendations}

\subsection{Characterization}

The technical team proposes characterization efforts that initially use passive vapor sampling to design a dynamic characterization strategy to delineate the extent of the plume and provide data 
for final remedial designs. The dynamic characterization strategy incorporates real-time groundwater contaminant concentration measurements using direct-push sensors, groundwater samples, and a mobile on-site laboratory for VOC analyses. The data gathered in the field are used to guide further characterization locations to reduce uncertainty and data gaps and refine the site conceptual model. The dynamic characterization strategy typically reduces costs by reducing the number of field deployments, time in the field, and number of samples sent for certified analysis. Table 3 summarizes the potential characterization methods, review team recommendations, and issues associated the technologies. An example of an efficient and effective implementation strategy for these technologies that is specific to the Building 100 plume is presented in Section 4.0 of this report. 
Table 3. Characterization Matrix

\begin{tabular}{|c|c|c|}
\hline Technology Description & $\begin{array}{c}\text { Review Team } \\
\text { Recommendation }\end{array}$ & Issues, Conditions, and Interdependencies \\
\hline $\begin{array}{l}\text { Passive Vapor Sampling Under Bldg 100: } \\
\text { Proprietary materials adsorb hydrophobic } \\
\text { contaminants and provide relative } \\
\text { concentrations below the slab. Holes are } \\
\text { drilled through the slab for access to the soil, } \\
\text { the samplers are placed in the holes, and the } \\
\text { top is sealed. The samplers are left in place } \\
\text { for approximately } 2-4 \text { weeks, then are } \\
\text { removed and shipped to a lab for analysis. } \\
\text { (www.beacon-usa.com). Other vendors are } \\
\text { available. }\end{array}$ & $\begin{array}{l}\text { Recommended } \\
\text { Provides a qualitative } \\
\text { approximation of the source } \\
\text { area plume under } \\
\text { Building } 100 .\end{array}$ & $\begin{array}{l}\text { - Access to building for appropriate distribution of samplers may } \\
\text { be limited. } \\
\text { - Appropriate sealing of slab boreholes while the samplers are } \\
\text { deployed is essential, since the building is under positive } \\
\text { pressure. } \\
\text { - Technology provides qualitative not quantitative results. } \\
\text { - Correlation between groundwater concentrations and passive } \\
\text { samplers will aid in interpretation. } \\
\text { - Relative concentrations will guide the need and locations of } \\
\text { groundwater sampling and installation of monitoring and/or } \\
\text { treatment wells under the building. }\end{array}$ \\
\hline $\begin{array}{l}\text { Passive Vapor Sampling on the South and } \\
\text { East Side of Building 100: The samplers are } \\
\text { placed } 1 \text { to } 2 \mathrm{ft} \text { deep in the soil at } 40-\mathrm{ft} \text { lateral } \\
\text { intervals and are left in place for } \\
\text { approximately } 2-4 \text { weeks, then are removed } \\
\text { and shipped to a lab for analysis. }\end{array}$ & $\begin{array}{l}\text { Recommended } \\
\text { Provides a qualitative } \\
\text { representation of the width of } \\
\text { the plume migrating from } \\
\text { beneath the building. }\end{array}$ & $\begin{array}{l}\text { - Technology provides qualitative not quantitative results. } \\
\text { - Correlation between groundwater concentrations and passive } \\
\text { samplers will aid in interpretation prior to invasive sampling. } \\
\text { - Relative concentrations will guide the need and locations of } \\
\text { groundwater sampling and installation of monitoring and/or } \\
\text { treatment wells near the building. }\end{array}$ \\
\hline $\begin{array}{l}\text { Sample Southeast Pond Sediments for } \\
\text { cVOCs: Use a "clam shell" sampler to collect } \\
\text { sediment samples from six locations in the } \\
\text { southeast pond to help evaluate plume width } \\
\text { to the south. Place samples into containers } \\
\text { according to laboratory protocol. }\end{array}$ & $\begin{array}{l}\text { Recommended } \\
\text { Provides a qualitative } \\
\text { representation of the width of } \\
\text { the plume migrating from } \\
\text { beneath the building. }\end{array}$ & $\begin{array}{l}\text { - Simple sampling technique. } \\
\text { - May not provide exact soil concentration if ponds are recharging } \\
\text { the aquifer. } \\
\text { - May help determine need for downgradient treatment. } \\
\text { - Only TCE, DCE and vinyl chloride should be reported. }\end{array}$ \\
\hline $\begin{array}{l}\text { Sample Southeast Pond for Water Quality } \\
\text { Parameters: Lower a multiparameter } \\
\text { sampling tool (YSI or similar) to the bottom } \\
\text { of the pond and measure parameters such as } \\
\text { dissolved oxygen and oxidation-reduction } \\
\text { potential to determine aquifer connectivity. }\end{array}$ & Recommended & $\begin{array}{ll}\text { - } & \text { Simple sampling technique } \\
\text { - } & \text { May help determine PRB design }\end{array}$ \\
\hline
\end{tabular}




\begin{tabular}{|c|c|c|}
\hline Technology Description & $\begin{array}{c}\text { Review Team } \\
\text { Recommendation }\end{array}$ & Issues, Conditions, and Interdependencies \\
\hline $\begin{array}{l}\text { Dynamic Subsurface Characterization: } \\
\text { A multiphased approach using direct-push } \\
\text { techniques with a membrane interface probe } \\
\text { (MIP) and depth-discrete groundwater } \\
\text { sampling with a mobile lab. Duplicate } \\
\text { samples can be collected and sent to a } \\
\text { certified lab where contamination is found. } \\
\text { This approach allows plume chasing by } \\
\text { stepping out from higher concentration to } \\
\text { lower concentration to define the plume } \\
\text { boundary. Install } 0.75 \text {-inch-diameter PVC } \\
\text { piezometers in each of the zones where } \\
\text { contamination is found. The process will } \\
\text { involve stepping out directly from the south } \\
\text { side of the building where the plume } \\
\text { emanates from under the building. }\end{array}$ & $\begin{array}{l}\text { Recommended. } \\
\text { Provides definitive plume } \\
\text { delineation for the distal } \\
\text { portion of the plume outside } \\
\text { the building. }\end{array}$ & $\begin{array}{l}\text { MIP provides qualitative results with detection limits greater } \\
\text { than approximately } 200 \mu \mathrm{g} / \mathrm{L} \text { depending on the detector used } \\
\text { (FID, XSD, ITMS). } \\
\text { - Groundwater sampling with direct-push techniques is common } \\
\text { practice. } \\
\text { - Ease of obtaining push site approval during plume chasing. } \\
\text { - Availability and costs of a mobile lab for on-site groundwater } \\
\text { analysis within time constraints. } \\
\text { - Site clearance for piezometer installations. } \\
\text { - Piezometers can be used for phased remediation. }\end{array}$ \\
\hline $\begin{array}{l}\text { Dynamic Subsurface Characterization Under } \\
\text { Building 100: } \\
\text { A multiphased approach using direct-push } \\
\text { techniques (mobile systems for use inside } \\
\text { buildings) with an MIP and depth discrete } \\
\text { groundwater sampling with a mobile lab. } \\
\text { Duplicate samples can be collected and sent } \\
\text { to a certified lab where contamination is } \\
\text { found. This approach allows plume chasing } \\
\text { by stepping out from higher concentration to } \\
\text { lower concentration to define the plume } \\
\text { boundary. Small-diameter PVC piezometers } \\
\text { can be installed in each of the zones where } \\
\text { contamination is found. }\end{array}$ & $\begin{array}{l}\text { Recommended. } \\
\text { Provides definitive plume } \\
\text { delineation for the plume } \\
\text { under the building }\end{array}$ & $\begin{array}{l}\text { - MIP provides qualitative results with detection limits greater } \\
\text { than approximately } 200 \mu \mathrm{g} / \mathrm{L} \text { depending on detector used (FID, } \\
\text { XSD, ITMS). Verification of MIP performance is essential. } \\
\text { - Groundwater sampling with direct-push techniques is common } \\
\text { practice. } \\
\text { - Locations and timing of sampling will be dictated by occupants' } \\
\text { infrastructure and schedules. } \\
\text { - Availability and costs of a mobile lab for on-site groundwater } \\
\text { analysis within time constraints. } \\
\text { - Piezometers can be used for phased remediation. }\end{array}$ \\
\hline
\end{tabular}




\subsection{Remediation}

\subsubsection{Bioremediation}

There are several general requirements for developing sustainable bioremediation (i.e., a longterm treatment zone) within the flow path of a contaminant plume. For chlorinated solvents, these typically include (1) creation of geochemical conditions favorable to the desired reactions (e.g., proper $\mathrm{pH}$, low eH, sufficient macronutrients, low levels of competing electron acceptors), (2) a balance of sustainable sources of substrate hydrogen and hydrogen precursors, and (3) documentation and maintenance of organisms that are capable of degrading the target contaminants to nontoxic products (adding these if necessary).

The most common degradation pathway for TCE is reductive dechlorination. Reductive dechlorination is an anaerobic process in which the chlorinated compounds serve as the terminal electron acceptors, as opposed to oxygen, which is the terminal electron acceptor during aerobic respiration. The dehalogenation process involves removing a chlorine atom from the alkene molecule and replacing it with a hydrogen atom. A carbon source addition enhances reductive dechlorination efficiency by providing the bacteria with organic carbon that is required for macromolecule production and an electron donor that is required for energy production. Lack of suitable carbon sources and electron donors is often the limiting factor for biodegradation in formations below the root zone.

The sequence of degradation reactions traditionally documented for chlorinated compounds, starting with TCE, is:

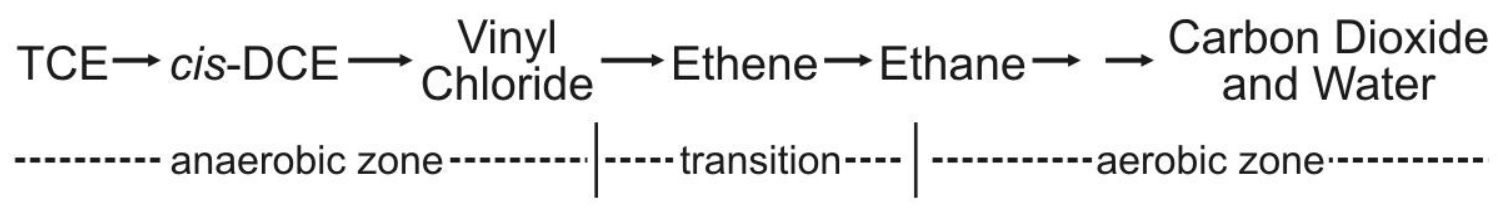

Other reactions also occur such as beta elimination (fast), co-metabolism of TCE (relatively slow), oxidation and co-metabolism of cis-DCE (moderate rates), and oxidation of vinyl chloride (fast).

In the reductive dechlorination process, microorganisms replace chlorine atoms with hydrogen, forming more-reduced products. In this process, TCE is subsequently reduced to cis-1,2-DCE, vinyl chloride, and eventually to the nontoxic end products ethene and ethane. Highly chlorinated compounds (e.g., TCE) are more susceptible to reductive dechlorination than less-chlorinated compounds (e.g., vinyl chloride) because they are more oxidized. Therefore, microorganisms that carry out the conversion of TCE to cis-DCE are relatively common and can survive in a variety of environments. The key organisms that can perform the complete anaerobic conversion of chlorinated ethenes to ethane are Dehalococcoides ethenogenes (DHC). This species requires strongly reducing conditions and circumneutral $\mathrm{pH}$ values for strong growth and effective chlorinated solvent conversion. Several commercial strains of DHC are readily available for sites where natural populations of DHC are not present (addition of DHC during remediation can reduce technical uncertainty and increase confidence that the degradation 
process will operate effectively). Partial reductive dechlorination (i.e., terminating at cis-DCE in the anaerobic treatment zone) is sometimes observed but is not necessarily a problem. While cis-DCE is relatively difficult to degrade anaerobically, it is fairly easy to biodegrade aerobically (McCarty, 2002). Therefore, as cis-DCE migrates out of an anaerobic treatment zone, it will degrade readily in the presence of oxygen.

A variety of organic substrates and other electron donors have been developed and successfully tested over the years. These include soluble substrates (e.g., lactate, molasses, whey, glycerol, and other soluble sugars/carbohydrates), emulsions of insoluble liquids (e.g., emulsified vegetable oil), insoluble liquid substrates (e.g., vegetable oil), insoluble viscous reagents such as innovative proprietary polymers of lactate. Solid carbon substrates (including chitin, mulch, peat or bark) and gases (e.g., hydrogen) have also been tested but with more limited experience. Combinations of organic carbon substrates and zero-valent iron (ZVI) are also commercially available. These amendments employ both the traditional biological dechlorination pathway as well as a rapid abiotic dechlorination mechanism (beta elimination), which reduces the production of unwanted intermediate byproducts such as vinyl chloride. The addition of ZVI also enhances the development of highly reducing conditions, which in turn fosters biological (DHC) success. Finally, ZVI can actively persist in the subsurface for several years.

Selection of the appropriate electron donor depends on site-specific needs related to deployability (mobility, density, etc.) and sustainability (longevity in the target setting for the target plume). A successful and sustainable biodegradation application often requires a balance of rapidly metabolized carbon substrate and more persistent organic carbon.

The geochemistry of the aquifer is critical for effective bioremediation. DHC cultures are strict anaerobes and are most effective near neutral $\mathrm{pH}$ and strong reducing conditions. Table 4 provides the significant geochemical parameters needed for effective reductive dechlorination with DHC along with average values from the Building 100 site. The conditions at the site are conducive to stimulate reductive dechlorination with the addition of a carbon source such as emulsified oil.

Table 4. Geochemical Parameters for Reductive Dechlorination

\begin{tabular}{|l|c|c|}
\hline \multicolumn{1}{|c|}{ Parameter } & Optimal Conditions & $\begin{array}{c}\text { Pinellas } \\
\text { Average Values }\end{array}$ \\
\hline Dissolved Oxygen & Low to zero & $1.5 \mathrm{mg} / \mathrm{L}$ \\
\hline $\mathrm{Ph}$ & 5.5 to 8 & 6 to 7 \\
\hline Alkalinity (buffering capacity) & Present & $200 \mathrm{mg} / \mathrm{L}$ \\
\hline Sulfate & $<20$ & $350 \mathrm{mg} / \mathrm{L}$ \\
\hline Nitrate & $<1$ & $0.4 \mathrm{mg} / \mathrm{L}$ \\
\hline Oxidation-Reduction Potential & Negative & $-100 \mathrm{millivolts}$ \\
\hline
\end{tabular}

$\mathrm{mg} / \mathrm{L}=$ milligrams per liter

The review team consensus is that enhanced in situ bioremediation is potentially viable and is conditionally recommended for addressing the Building 100 contamination (contingent upon developing cost-effective access and delivery using methods that have acceptable uncertainties 
and low technical/cost risks). The addition of ZVI to organic carbon substrates offers an important enhancement to this process by enabling an abiotic pathway for contaminant dechlorination and enhancing reducing conditions in the subsurface.

\subsubsection{Permeable Reactive Barrier}

Permeable reactive barriers (PRBs) use reactive material placed in the subsurface to sorb, precipitate, or chemically or biologically transform contaminants in groundwater flowing through the PRB. PRBs are able to remediate a number of contaminant classes and have been effective in treating environments that were recalcitrant to management through other remediation methods. PRBs are designed as passive treatment systems, with groundwater typically flowing under a natural gradient. Because contaminated groundwater must passively flow through the treatment zone, a thorough understanding of plume boundaries, aquifer hydrogeology, and reactive media characteristics is essential. The permeability of emplaced reactive materials must equal or exceed that of the aquifer over the operational lifespan of the PRB to ensure that contaminated groundwater flows through, not around, the reactive zone. PRBs generally have low maintenance costs and few operational costs aside from long-term performance monitoring, which is necessary to ensure sustained functioning of the system.

A number of reactive materials are available to treat TCE as groundwater flows through a PRB. Many PRBs rely on ZVI to abiotically reduce and dehalogenate TCE and related chlorinated solvents. Recently, the selection and deployment of biowall systems that use long-lived solid organic materials such as mulch, compost, and peat has expanded - these systems biologically reduce and dehalogenate chlorinated solvents. The lifespans of ZVI and biowall systems are determined by reaction and inactivation of iron or by depletion of carbonaceous substrates over time, respectively. Liquid organic carbon can be added to a ZVI PRB to increase dechlorination with biological reductive dechlorination. The lifespan of a biowall can be increased by augmentation with liquid (or slurried) carbon sources, extending a system's useful life by a decade or longer (AFCEE, 2008).

Infrastructure for substrate addition should be incorporated during dynamic characterization activities. As with other PRBs, long-term performance monitoring is essential.

The review team believes that reductive PRBs are a viable option for the Building 100 plume. In particular, the team recommends a ZVI plus organic carbon PRB transverse to the contaminant flow path on the south and eastern sides of the building. A provision for future revitalization (via bioaugmentation or liquid carbon substrate injections) would provide a cost-effective, viable contingency. This technology will have little benefit upgradient of the barrier (i.e., in the source zone) and may adversely impact general water quality (e.g., low oxygen, high iron) downgradient of the wall and potentially impact water quality in groundwater discharge areas near the PRB.

\subsubsection{In Situ Chemical Oxidation Treatment}

In situ chemical treatment uses reactive amendments to destroy contaminants in the target zone. In situ chemical oxidation (ISCO) is an important technology that has proven to be both prudent and effective for cleanup of appropriate sites (EPA, 1999). Data from ISCO case studies provide a general framework for identifying promising sites and for optimizing design and implementation. This framework has three major elements: (1) confirming appropriate target 
contaminant mass and concentration, (2) matching the oxidant chemistry and longevity to the site conceptual model, and (3) developing a practical access and delivery method for site conditions and target contaminant geometry. Each of these elements is briefly discussed below.

Appropriate applications of ISCO for chlorinated alkenes generally include limited areas that are either not easily degraded by reductive methods (e.g., because of toxic concentrations) or require more-rapid cleanup. ISCO is relatively ineffective for treating large DNAPL pools due to limited contact and is generally inappropriate for large, dilute plumes because of the large amount of oxidant (and high cost) required due to limited persistence in the subsurface.

A number of oxidants are available, each having a slightly different profile of reactivity, longevity, and deployability, and each having identifiable advantages and disadvantages. Common oxidants include:

- Oxygen (delivered as air) - the most inexpensive oxidant and successful in degrading several common contaminants, including vinyl chloride and cis-DCE. The injection of air as air sparging may be used as a precursor to the application of other chemical oxidants to reduce the total oxidant demand of the target volume and therefore the cost (because less chemical oxidant is required) of the project.

- Permanganate - reactive reagent that can be applied as a liquid or blended in as a solid, does not require activation, very successfully used for chlorinated alkenes at many sites, generates treated water that is purple, moderate lifetime (from weeks to several months).

- Persulfate - reactive reagent that can be applied as a liquid or blended in as a solid, does not require activation for treating chlorinated alkenes, moderate lifetime depending on oxidant demand (from weeks to several months), converts to sulfate, which may impede subsequent reductive dechlorination.

- Hydrogen peroxide - highly reactive liquid reagent, often activated with reduced iron for a "modified Fenton's" reaction, reformulation with other chemicals to stabilize peroxide has been successful at some sites; relatively short lifetime in all cases, even if stabilized (days to weeks), produces heat and gas, which may make contact with contaminant and subsequent injections difficult, particularly for shallow injections.

Table 5 summarizes the potential remediation methods, review team recommendations, and issues associated with implementation of the technologies. 
Table 5. Remediation Technology Matrix

\begin{tabular}{|c|c|c|}
\hline Technology / Description & Review Team Recommendation & Issues, Conditions, and Interdependencies \\
\hline $\begin{array}{l}\text { Permeable Reactive Barriers: } \\
\text { Treatment zone downgradient to } \\
\text { reduce/destroy contaminants flowing through } \\
\text { the zone. (ZVI, ZVI + organic carbon, organic } \\
\text { carbon). ZVI-based (either with carbon or } \\
\text { without) would be preferable to encourage } \\
\text { abiotic (beta-elimination) reductive pathway. } \\
\text { Can be deployed by direct-push injection or } \\
\text { soil mixing (e.g., large-diameter auger, soil } \\
\text { blend). }\end{array}$ & $\begin{array}{l}\text { Potentially viable and conditionally } \\
\text { recommended. Microscale ZVI typically active } \\
\text { longer than } 10 \text { years. Deployed in plume path } \\
\text { at south and east ends of building. Can } \\
\text { potentially be augmented with additional } \\
\text { injection points or with sheet pile for funnel } \\
\text { and gate. }\end{array}$ & $\begin{array}{l}\text { Slightly more expensive than the enhanced } \\
\text { anaerobic bioremediation. Little upgradient } \\
\text { benefit (i.e., in the source zone); may } \\
\text { adversely impact general water quality near } \\
\text { groundwater discharge areas. }\end{array}$ \\
\hline $\begin{array}{l}\text { Enhanced Anaerobic Bioremediation } \\
\text { In situ bioremediation using electron donor } \\
\text { plus nutrients (e.g., phosphorous, nitrogen). } \\
\text { Can be deployed by direct-push injection or } \\
\text { soil mixing (e.g., large-diameter auger, soil } \\
\text { blend). }\end{array}$ & $\begin{array}{l}\text { Potentially viable and conditionally } \\
\text { recommended. }\end{array}$ & $\begin{array}{l}\text { May not overcome degradation stalling at } \\
\text { cis-DCE and vinyl chloride. May require } \\
\text { periodic reapplication. Little upgradient benefit } \\
\text { (i.e., in the source zone); may adversely impact } \\
\text { general water quality near groundwater } \\
\text { discharge areas. }\end{array}$ \\
\hline $\begin{array}{l}\text { Bioaugmentation/Using DHC Pinellas } \\
\text { Potentially recover groundwater from } \\
\text { downgradient of northeast bioinjection and } \\
\text { inject. }\end{array}$ & $\begin{array}{l}\text { Potentially viable and conditionally } \\
\text { recommended. Complete dechlorination is } \\
\text { stalled for some reason; cause may be lack of a } \\
\text { sufficient density of DHC. }\end{array}$ & $\begin{array}{l}\text { Bioaugmentation may not overcome current } \\
\text { growth limitations. }\end{array}$ \\
\hline $\begin{array}{l}\text { Air Sparging } \\
\text { Can be deployed by direct-push injection. } \\
\text { Least expensive actively deployed remediation } \\
\text { technology. }\end{array}$ & $\begin{array}{l}\text { Potentially viable and conditionally } \\
\text { recommended for distal plume. Can oxidize } \\
\text { vinyl chloride will also convert arsenite to } \\
\text { arsenate }(10 \times \text { less mobile). }\end{array}$ & Contrary to ambient redox conditions. \\
\hline $\begin{array}{l}\text { In Situ Chemical Oxidation } \\
\text { Can be deployed by direct-push injection or } \\
\text { soil mixing (e.g., large-diameter auger, soil } \\
\text { blend). Permanganate, persulfate, modified } \\
\text { hydrogen peroxide. }\end{array}$ & $\begin{array}{l}\text { Potentially viable and conditionally } \\
\text { recommended for distal plume. Easily oxidizes } \\
\text { chlorinated ethenes, especially vinyl chloride. } \\
\text { Will also convert arsenite to arsenate ( } 10 \times \text { less } \\
\text { mobile). }\end{array}$ & $\begin{array}{l}\text { Oxidant lifetimes are relatively short (days to } \\
\text { months) and may require multiple applications } \\
\text { unless upgradient source is eliminated. Public } \\
\text { perception issues (e.g., purple water) and } \\
\text { secondary drinking water standards (e.g., } \\
\text { sulfate exceedances). Heat and gas formation } \\
\text { may impede distribution in case of hydrogen } \\
\text { peroxide. Contrary to ambient redox } \\
\text { conditions. }\end{array}$ \\
\hline
\end{tabular}




\subsubsection{Example of Phased Remedial Strategy for Building $\mathbf{1 0 0}$}

The team has assembled a descriptive example to illustrate a potential remedial strategy for the Building 100 source and plume. This combined remedy example assumes (1) subsurface access primarily using direct-push technology, (2) treatment using pressure injection of amendments in the source zone to reduce mass and flux, (3) development of a PRB to significantly reduce downgradient contamination, and (4) possible direct treatment of the existing off-site plume.

The central action in this suite of technologies is reductive dechlorination (both biological and abiotic) in the source zone and the PRB. Figure 12 is a schematic of one realization of the reductive dechlorination treatment.

Immediate installation of a PRB will help to reduce the downgradient flux of contaminants. Because of the potential stall of natural biological dechlorination despite a reasonable concentration of total organic carbon and the likely presence of fully dechlorinating DHC bacteria, we recommend applying ZVI with organic carbon and nutrients. The ZVI would both enable beta elimination (direct dechlorination through short-lived acetylene daughters to the end compounds of ethene and ethane) and create significantly enhanced reducing conditions. The addition of organic carbon and nutrients should help complete the conventional biological reductive dechlorination pathway to ethene and ethane. Concentrated DHC may be applied as well, although preferably it would be applied after the organic carbon application. Possible alternatives include ZVI applied without organic carbon or organic carbon applied without ZVI. Approximate commercial cost range of microscale ZVI is $\$ 0.50$ to $\$ 2$ per pound; the approximate commercial cost range of organic carbon is $\$ 1$ to $\$ 5$ per pound; and the approximate commercial cost range of combined ZVI and organic carbon is $\$ 1.75$ to $\$ 4$ per pound. The application rate is typically between $0.1 \mathrm{wt} \%$ to $2 \mathrm{wt} \%$ of the total mass of the treated volume. The application of ZVI alone or with carbon is protected by patent but may be accessed through several licensed vendors.

The PRB will transect the plume immediately outside the southern and eastern sections of the building. The treatment amendments could be applied directly using soil mixing or excavation techniques (e.g., large-diameter auger, modified excavator deep soil mixer) or by injecting through direct-push rods. For this example, we have assumed amendment injection through direct-push rods at multiple depths. Daily injection commercial rates range from approximately $\$ 3000$ to $\$ 6000$ per day per crew, and each crew can typically inject between 1000 pounds and 5000 pounds of amendment per day.

For a 300 -ft-long by 20 -ft-wide by 25 -ft-thick PRB, assuming an injection radius of $10 \mathrm{ft}$, between 15 and 20 injection locations will be required (assuming some overlap). The treatment volume is 150,000 cubic feet ( 8250 tons). If the injection volume is approximately 850 gallons per location, a total of approximately 17,000 gallons containing 17,000 pounds of ZVI and organic carbon or approximately $1 \mathrm{lb} /$ gal would be injected. The total commercial cost of this application would be approximately $\$ 100,000$ and would take approximately 12 days to complete. This example approximates a PRB application to a transect perpendicular to the apparent flow path of the plume on the south side of the building.

Some potential variations on the PRB include additional length of the PRB and sheet pile walls installed to create a funnel and gate treatment system. Although Figure 12 depicts a single row of 
injection locations (and an unrealistically small number of injection points in this case), more than one row of injections is often used. The added injection row improves amendment distribution and the effectiveness of the PRB by compensating for variations in contaminant distribution and permeability. Installation of multilevel wells for monitoring or subsequent injection of additional substrate or DHC bacteria could also be useful. Tracking of the radius of influence may be useful to ensure that the PRB injection location comprehensively covers the proposed treatment line. Some potential issues include the creation of a strongly reductive zone, which may result in reductive conversion of chemical species or compounds, such as reduction of sulfate to sulfide (strong smells in pond) or conversion of arsenate to more mobile arsenite.

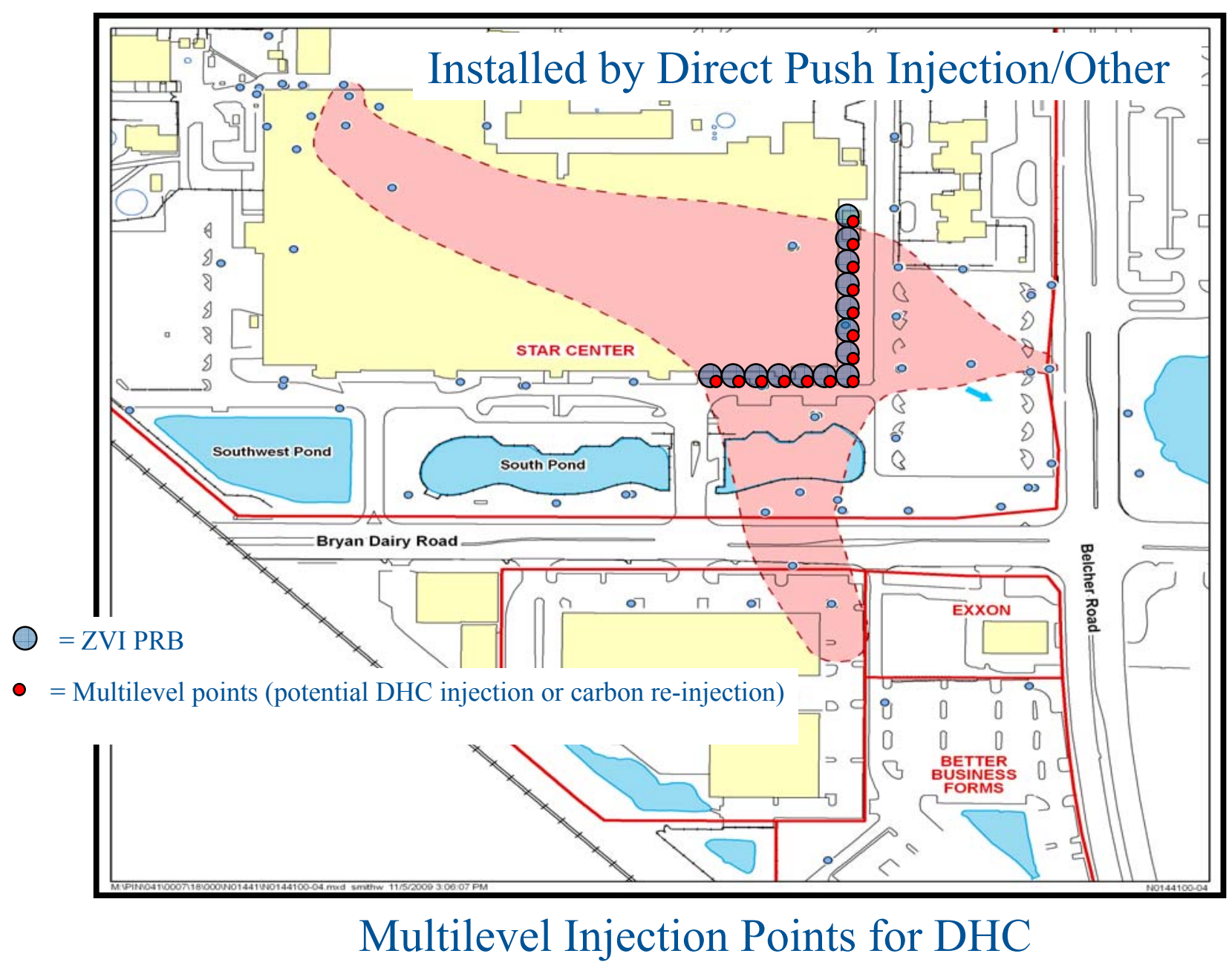

Figure 12. Recommened location for ZVI Permeable Reactive Barrier

\section{Plume Downgradient of PRB}

The creation of a strong reducing zone immediately downgradient of the PRB is desired for dechlorination of contaminants but may result in unwanted reduced compounds in areas where groundwater is exposed, such as the south pond. Installation of an aeration system (e.g., fountain) in the pond could mitigate the creation of sulfides and potential odors. 
With the installation of a PRB near the building that effectively eliminates or diminishes additional contaminant flux downgradient, it may be possible to make the case for a monitored natural attenuation remedy. Apart from the non-cVOC issues resulting from the creation of strongly reducing groundwater by installing the ZVI-based PRB, the continued diminishing of the contaminant mass by dechlorinating conversion should shrink the downgradient plume over time. If there are compelling reasons for decreasing the time to remediate the isolated downgradient plume or to address issues associated with a highly reducing groundwater front, or if the PRB near the building has not sufficiently reduced contaminant flux, then additional treatment can be considered. As performed near the building, additional treatment may include the installation of a PRB, or alternatively it may include distributed or targeted spot treatments by injection of amendment. Both the lateral and vertical placement of this treatment would be determined by the characterization work performed before treatment began (as described in Section 3.1). Apart from the spatial determination of additional downgradient treatment, a strategic choice must be made about the type of remediation for this area, which we hope has been largely cut off from renewed contaminant influx. Although the prevailing ambient redox conditions at the site are reducing, and these conditions should normally not be opposed, because of its presumed isolation, the temporary creation of oxidizing conditions may be considered as an alternative to further enhancing reduction. Other compelling reasons for using oxidants along the site boundaries include more stringent contaminant cleanup criteria off site, potential desire for more rapid results, and moderate total oxidant demand measurements of soil and groundwater from the Pinellas site. Natural background concentrations of arsenic in this area are relatively high ( 0.0025 to 0.02 milligram per liter $[\mathrm{mg} / \mathrm{L}])$. Reducing conditions favor the formation of arsenite, which is approximately 10 times more soluble (and more mobile) than the moreoxidized arsenate. Thus, the creation of stronger reducing conditions may exacerbate naturally high background arsenic concentrations and create regulatory issues off site.

Assuming the mitigation of off-site contamination, multilevel injection points will be installed on the southern and eastern site boundaries (within the footprint of the plume as determined by prior characterization). These direct-push, small-diameter PVC injection points will enable remedial options. One realization of a remedial strategy using oxidation might include initial, low-flow air sparging in the deeper injection wells. Air sparging may completely mitigate contamination, or at least reduce oxidant demand in the area. If this low-cost strategy does not fully prevent off-site migration, the addition of chemical oxidants through the multilevel injection wells will remediate the target contaminants. Several chemical oxidants will be effective for the chlorinated ethenes in this portion of the plume, including, in order of preference, permanganate (potassium or sodium), sodium persulfate, and modified hydrogen peroxide. Advantages and issues for these oxidants are discussed in Section 3.2.3. Additional injections can be performed as needed until the plume is eradicated.

An example of a scenario using air sparging followed by potassium permanganate injection on the southern site boundary would include injection wells covering approximately $200 \mathrm{ft}$ along the border, south of the South Pond. Approximately 13 multilevel well locations would be used (these wells will be installed during the characterization activities). Air would be injected in the wells at the lowest depth and continued at low-flow rates (approximately 1 to 3 cubic feet per minute per well) until 5 to 10 pore volumes were injected. Between 5 and 15 days of air sparging would be expected to be sufficient for reducing chemical oxidant demand. Photovoltaic-powered 
air pumps would easily meet the requirements for air sparging in this area and would cost (commercially) between $\$ 1000$ and $\$ 3000$ per well for installation and materials.

Following air sparging, solutions of permanganate (between 1 percent and 4 percent) would be injected in the wells at appropriate depths. During each injection event, it is estimated that each well location would receive approximately 850 gallons of solution (sum of injectate at all depths in a given location). Each well location would receive between 100 and 400 pounds of permanganate at a cost of approximately $\$ 3$ per pound. Daily injection through well commercial rates range from approximately $\$ 1500$ to $\$ 5000$ per day per crew, and each crew can typically inject between 1000 gallons and 4000 gallons of amendment per day. The total cost for a permanganate injection event for this scenario is approximately $\$ 55,000$ and would take approximately 6 days to complete. Figure 13 is a cartoon depicting the scenario of treatment along the site boundaries. As with the other figures, this is an approximation of the described scenario and is used to illustrate the remediation concept.

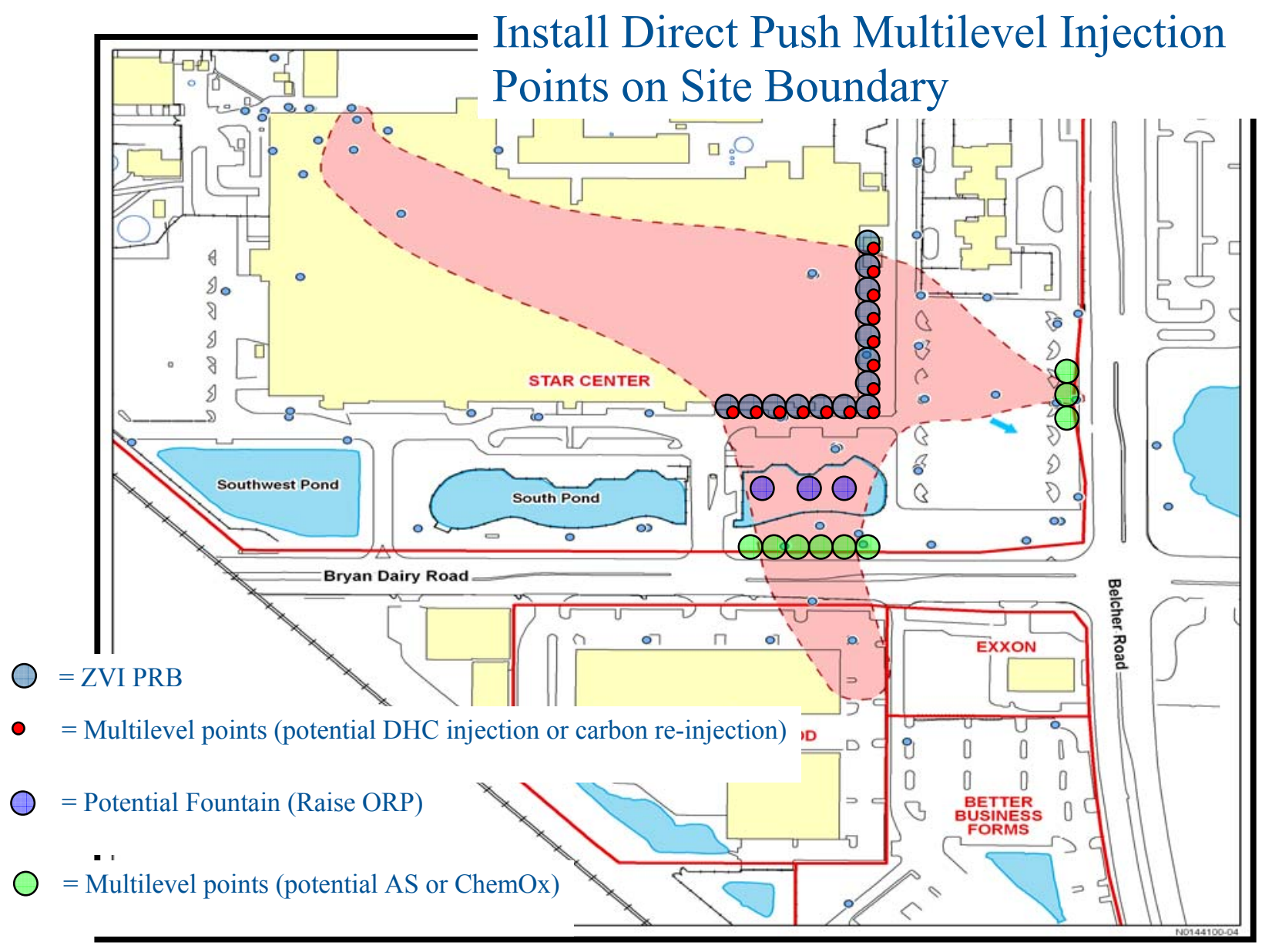

Potential Oxidation at Site Boundary

Figure 13. Proposed location of Treatment Line at the Site Boundary 


\section{Source Treatment}

We encourage injection of mobile organic carbon substrate immediately upgradient of the former drum storage area. Some carbon substrates have solvent properties (e.g., ethyl lactate) which may effectively reduce residual source beneath the building and "chase" the contaminant plume. To directly address the hot spots found during characterization in the building, spot injections may be conducted through injection wells. During the characterization activities, small-diameter injection wells will be installed at locations and depths with detected contaminant. In addition, existing wells may be used for injection of amendments. We understand that injections inside the building may be difficult to execute for a variety of logistical reasons. Activities inside the building will need to be fortuitous and opportunistic. We recognize that treatment will probably not be able to be applied in a manner that will comprehensively address the plume (i.e., an injection grid will probably not be possible), however any treatment in the source area will likely be beneficial.

Alternatively, carbon and nutrient injections upgradient of the former drum storage area can be applied systematically with comprehensive spatial coverage and should encourage accelerated remediation in the source area as the injectate is swept downgradient. Although this strategy essentially chases the mobile plume, it will enhance reduction of the residual, less mobile contamination. Figure 14 provides a conceptual strategy for treating the source area, plume below the building, and preventing additional offsite migration.

It should be noted that installation of direct-push wells will require large enough (e.g., 3-inch) diameter push casing to allow proper installation of sand filter, followed by bentonite and grout around small-diameter ( 0.75 inch or 1 inch) PVC. PVC screen may be 10 or 20 slot and should be installed with well sock material around screen. The selected contractor should have experience installing direct-push injection wells. 


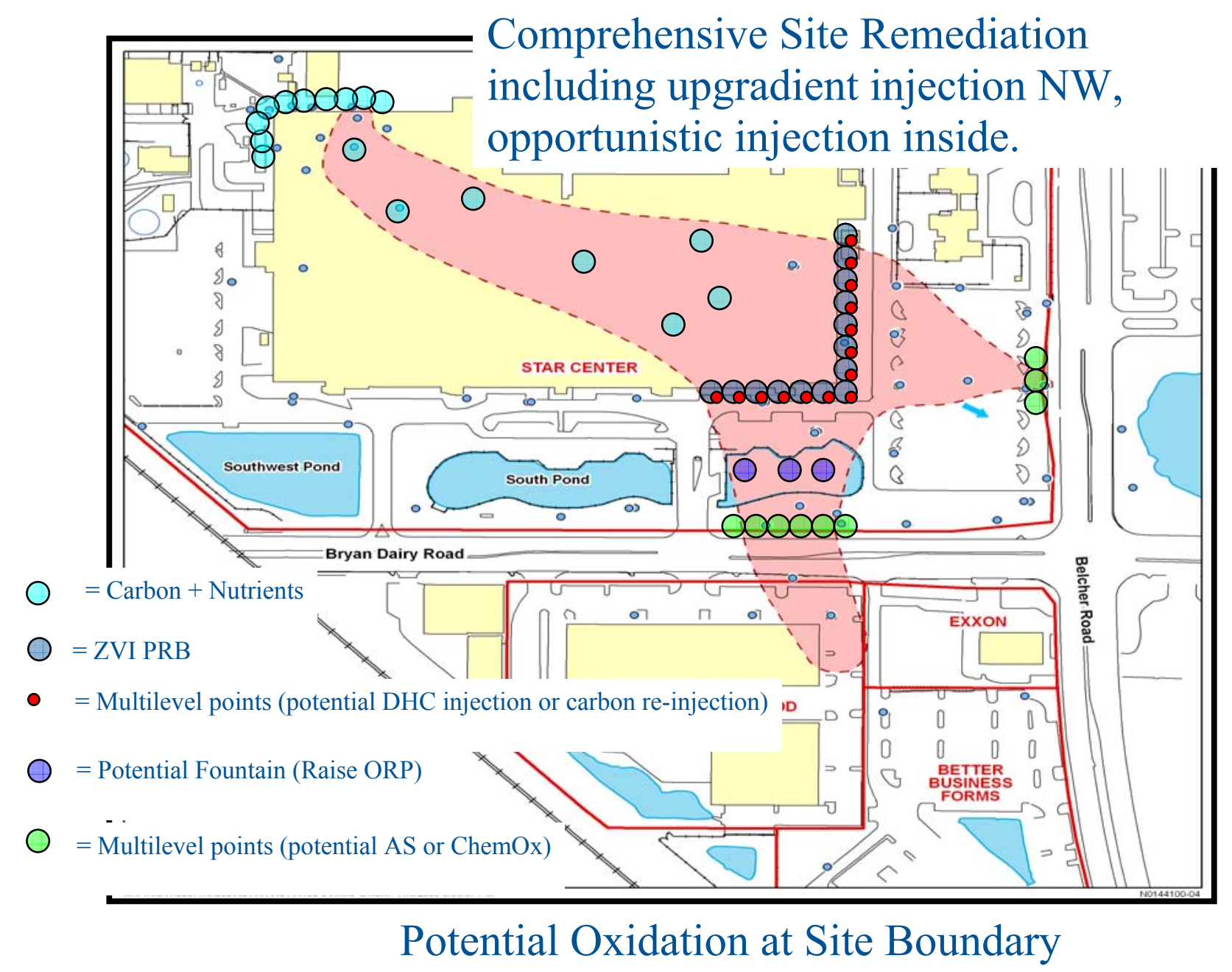

Figure 14. Location of source area sweep and below building treatment

This section was intended to provide a rough concept for deployment and is not prescriptive. Instead, the intent here is to provide a simple example and to encourage the Pinellas team, DOE, contractor, and regulators to work together to develop their own creative and effective solution for the Building 100 Area source and plume. 


\subsection{Implementation of Phased Dynamic Strategy}

The team recommends implementation of a phased characterization strategy based on a dynamic work plan approach in which real-time data collected in the field can be used to modify the design of the field operations for both characterization and remediation activities. The benefits of the dynamic work plan include minimizing field mobilizations, reducing the need for redundant phases of implementation, lower site investigation costs, and accelerated schedule. The technical team proposes an initial screening characterization using passive vapor diffusion sampling to design a dynamic characterization strategy using minimally invasive tools, such as direct-push methods with various sampling capabilities, to provide data for final remedial designs.

The dynamic characterization strategy incorporates real-time groundwater concentration measurements using direct-push sensors, groundwater samples, and a mobile on-site laboratory for VOC analyses. The data gathered in the field are used to guide additional characterization locations to reduce uncertainty and data gaps and refine the site conceptual model. The dynamic characterization strategy typically reduces costs by reducing the number of field deployments, time in the field, and number of samples sent for certified analyses.

Implementation of the recommended dynamic work plan approach will require a subcontractor with significant experience with these methods. Two subcontractors with such experience who have demonstrated their capabilities to ensure successful dynamic characterization are Triad Environmental Solutions Inc. and KB Laboratories.

The integrated strategy is described by detailing site characterization and remediation activities in two general locations:

- In and near Building 100 (near the suspected source)

- In the distal plume (defined as on site, south of the South Pond and along the eastern boundary of the property, and off site, south of Bryan Dairy Road).

A flow diagram that describes recommended activities through a decision process is provided as Figure 15. On the left side of Figure 15, activities recommended for the "In and Near Building" locations are described, and on the right side of Figure 15, activities recommended for the distal plume are described. The following sections provide additional details. 
Integrated Strategy

(Dynamic Workplans)

In and Near Building
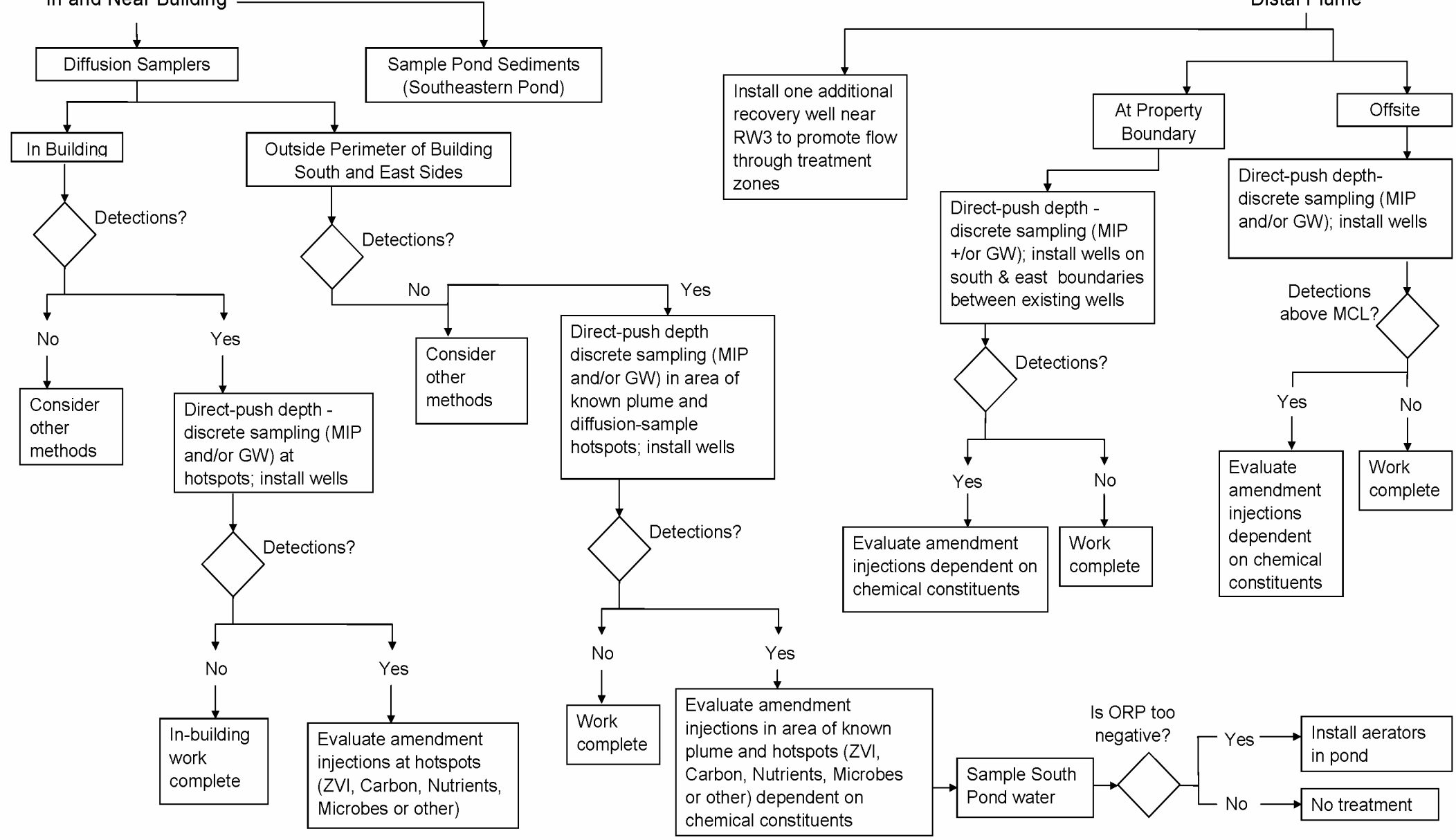

Figure 15. Activity Flow Diagram 


\subsection{Activities in and near Building 100}

\subsubsection{Passive Vapor Diffusion Sampling}

The first key activity is placement of passive vapor diffusion samplers both within and outside the perimeter of Building 100 on the south and east sides of the building where the contaminant plume is currently mapped. The in-building samplers will be installed below the floor by drilling small-diameter holes through the floor and capping with a replaceable seal. Passive vapor diffusion samplers are installed to collect vapor samples in sorbent traps over time (approximately 2 weeks). The samplers are retrieved after 2 weeks to 1 month, and the sorbent is analyzed for VOCs, as described in Table 3. Figure 16 is a map of proposed passive vapor diffusion sampler locations both within and outside the building. It is likely that not all proposed locations will be accessible, and the planned locations must therefore remain flexible, with an attempt to target the area under the currently mapped plume, possibly with greater sampling density in areas of suspected sources (optional second-phase investigation if necessary).

Pending the results of the passive vapor diffusion samplers, additional characterization may be recommended within the area of known hot spots. Further delineation of hot spots using passive vapor diffusion samplers should be considered, as they represent an inexpensive approach to plume delineation. Further delineation would require a second phase of passive vapor diffusion sampling. This decision will be dependent on the results of the initial passive vapor diffusion sampling. If no additional passive vapor diffusion sampling is required, the work activities should move to direct-push contaminant delineation as described below. 


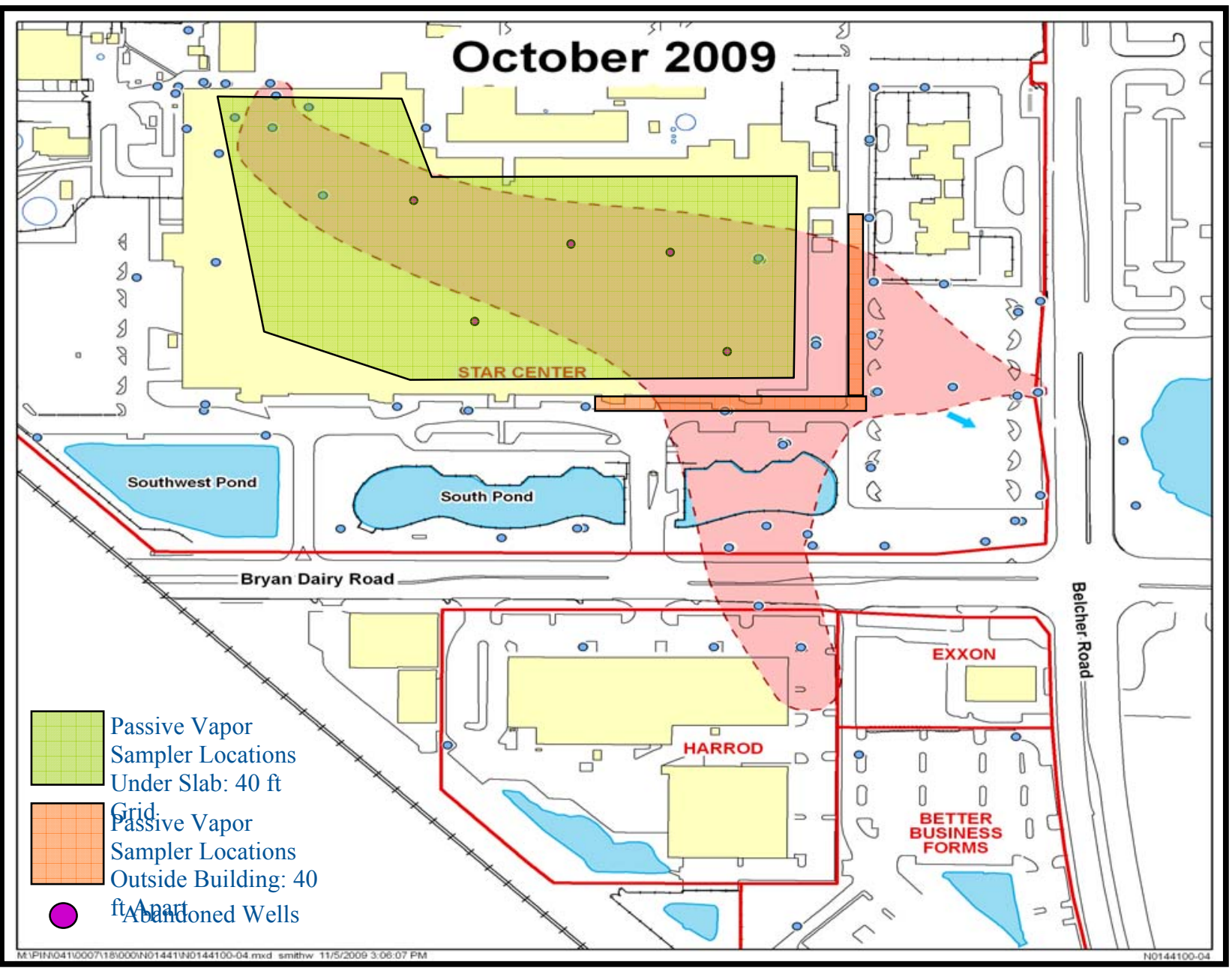

Figure 16. Proposed Locations for Passive Diffusion Samplers

\subsubsection{Direct-Push Contaminant Delineation Using Depth-Discrete Membrane Interface Probe and Groundwater Sampling}

If additional passive vapor diffusion sampling is not required, further hot-spot delineation is recommended using direct-push tools to perform membrane interface probe (MIP) and depth-discrete groundwater sampling with field analytical support. At the conclusion of this sampling, small-diameter wells should be installed as either monitoring points or potential injection points for future remedial amendment addition.

If the passive vapor diffusion sampling results show no detections even in known contaminated areas, other methods of characterization should be considered. We have not described specific alternative methods, because we have confidence that contaminants will be detected, as the current conceptual model identifies the original contaminant source to be under the building footprint.

Depth-discrete groundwater results from the in-building and building-perimeter samples should be evaluated for detections above the regulatory maximum contaminant level; these detections will be used as input for the amendment injection evaluation described in Section 4.1.3. The MIP 
should be used in known areas of contamination at the building perimeters (south and east) to evaluate the sensitivity and applicability of this tool for mapping contaminants farther downgradient, including off-site locations.

If the depth-discrete groundwater results indicate significant hot spots under the building that may require further investigation or delineation, and if access through the building floor is limited, directional drilling could be considered to obtain soil samples for analysis of VOCs and DNAPLs. This technology was used at the Fernald, Ohio, Site to sample beneath an existing facility. Four boreholes were drilled and four soil samples were collected in each of the boreholes for chemical and radiological analysis. Because of the expense of this approach, it should only be considered if vertical access through the building floor cannot be obtained. Figure 17 depicts the proposed areas for dynamic groundwater characterization.

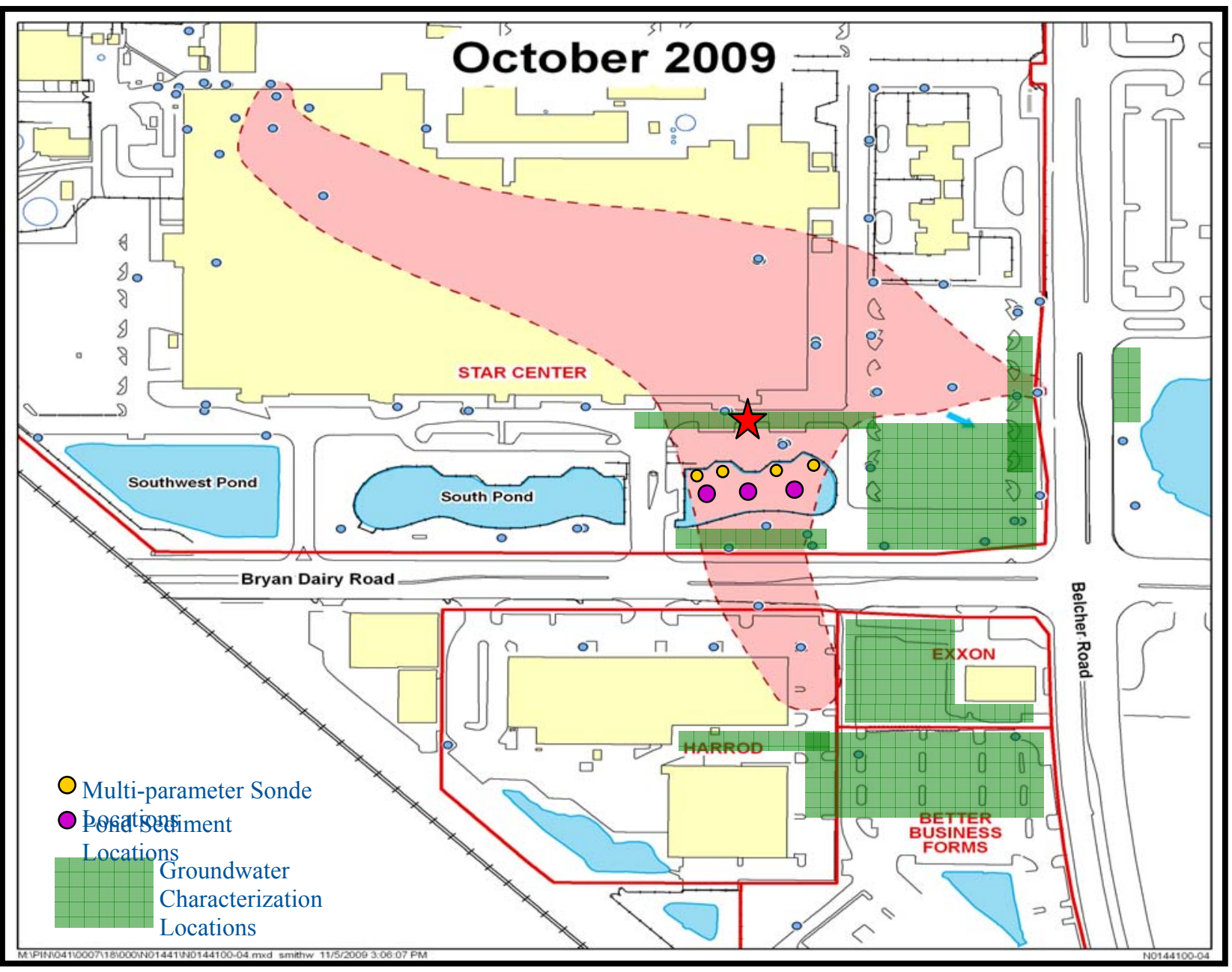

Figure 17. Location of Groundwater Samplers

\subsubsection{Amendment Injections}

If groundwater contaminants are detected above maximum contaminant levels, an evaluation of amendment injections should be considered both within the building and outside along the building perimeter. The team currently considers a row of amendment injection points at 
approximately 20 -ft centers in locations above where the currently mapped groundwater plume emanates from the southeastern portion of the building to be the minimum required. Additional injection points should be included based upon passive vapor diffusion sampling and groundwater quality results from both within and outside the building. It is possible that horizontal wells could be considered to access extreme hot spots, if no access through the floor inside the building can be gained. Costs for this type of access will be significantly higher than those for vertical access points.

The type of amendment to be injected should be evaluated according to the chemical constituents in the groundwater samples, that is, whether only TCE degradation products such as vinyl chloride are present or whether other VOCs are present as well The team believes it is likely that in this near-source area, the best amendment will build upon the natural reductive dechlorination currently occurring at the site. We recommend that the amendment include organic carbon, nutrients, ZVI, and possibly microbial augmentation.

\subsubsection{South Pond Sampling}

Sampling and analysis of the water and sediments in the eastern portion of the South Pond should be considered. A real-time multiparameter sonde that analyzes for $\mathrm{pH}$, oxidationreduction potential, temperature, conductivity, and dissolved oxygen should be used to collect data at 1-ft intervals until the sonde contacts the bottom of the pond. No laboratory analysis of samples is recommended. Three sediment samples should be collected as shown in Figure 17 for analysis of VOCs (including TCE, DCE, and vinyl chloride) and total organic carbon. Samples should be collected and analyzed during both the dry and rainy seasons to look for temporal variability. This proposed sampling is not critical, but the results would provide an excellent addition to the database. The additional data could enhance the current understanding of the conceptual model regarding connections between surface water and groundwater. The sample results could also help to resolve questions regarding nondetection of VOCs in groundwater at the southern property boundary in combination with higher concentrations in off-site locations south of Bryan Dairy Road.

\subsection{Distal Plume}

The distal plume is defined as any location south of the South Pond and on the eastern edge of the STAR Center property immediately west of Belcher Road. Distal plume activities are recommended in three locations: (1) along the southern property boundary where the currently mapped groundwater plume flows off site, (2) along the eastern property boundary where the groundwater plume is currently mapped adjacent to Belcher Road, and (3) off site on property south of Bryan Dairy Road where contaminants have been detected in groundwater samples.

\subsubsection{Direct-Push Contaminant Delineation Using Depth-Discrete MIP and Groundwater Sampling}

At the two property boundaries, south and east, further contaminant delineation should be performed using direct-push methods with depth-discrete sampling using the MIP and groundwater sampling to better delineate the distal plume at critical property boundary locations. Before this work can begin, similar characterization needs to be conducted adjacent to the 
building to enable calibration of the MIP in areas expected to contain higher concentrations of VOCs. Figure 17 (green boxes) shows the areas proposed for further contaminant delineation.

Pending field results, groundwater wells should be installed at hot spots to use for future monitoring or amendment injection. This additional plume delineation is needed to further understand the extent of the plume between and adjacent to existing wells.

On the property south of Bryan Dairy Road, further contaminant delineation should be performed using a dynamic sampling approach that involves direct push using depth-discrete MIP, groundwater sampling, and field analytical support. The currently proposed transects are recommended as an initial strategy, which should be modified based on field analytical results as samples are collected. The objective of this delineation effort is to fully delineate the plume during a single phase of field activity.

Groundwater sampling results from the distal plume samples should be evaluated for detections above maximum contaminant levels. If contaminant concentrations are elevated at the eastern boundary of the site, implying potential off-site migration beyond Belcher Road, additional delineation should be performed off site in this direction using the methods described above.

\subsubsection{Amendment Injection}

If the groundwater results in the off-site plume south of Bryan Dairy Road indicate hot-spot locations, amendment injections should be evaluated. The type of amendment should be based on the chemical constituents present in the groundwater samples. Because this downgradientmost portion of the plume is far from the original source, and we can assume that the plume source will be cut off by the PRB to be emplaced on the south and east sides of the building, it is possible that a different strategy from that of the near-building injections may be considered. Air sparging and chemical oxidation should be included in the evaluation for this part of the plume, as only daughter products may be present. The potential advantage of chemical oxidation is that it can produce rapid degradation results, a result that could be important when dealing with offsite plume situations with other landowners. However, if existing conditions are reducing, a reductive dechlorination approach may be preferable.

\subsubsection{Recovery Well Installation}

The team recommends the installation of an additional recovery well near RW-3 to increase the extraction rate in that area between Building 100 and the south property boundary. After installation of the PRBs, one near the building and one at the south property boundary, the recovery well can enhance flow of water through the barriers, thus accelerating treatment rates. The team believes that the site has already planned for such an action by incorporating sufficient infrastructure to treat additional volumes of contaminated groundwater.

\subsection{Recommended Decision Flow and Sequencing of Activities}

Figures 15 and 18 respectively show the recommended decision flow and sequence of activities that build upon rapid contaminant delineation. The process shown in the figures uses innovative methods to ensure full delineation in a single mobilization and produces results that enable 
decision-making regarding remedial activities. The contaminant plume delineation activities are all recommended to tie directly to decisions regarding remedial options and designs. In addition, sequencing promotes early deployment of remedial options in locations where remediation will demonstrate a proactive approach to produce actionable results such as (1) rapid source removal under or near the building, (2) treatment along the property boundaries to minimize further offsite migration, and (3) hot-spot treatment on off-site properties to rapidly reduce potential impacts to groundwater quality.

\section{Scheduling of Activities}

Passive Vapor Diffusion

Sampling In/Near Building
Depth Discrete MIP and GW

In Building
Depth Discrete MIP and GW

Near Building

Depth Discrete MIP and

GW Offsite

Depth Discrete MIP and

GW Site Boundaries

Inject Amendments at Evaluate Injection of Building Perimetervaluate Injezendments Offsite

Amendments Site Boundary

Figure 18 Suggested sequencing for of remediation and characterization.

\subsection{Other Recommendations}

\section{Monitored Natural Attenuation Strategy}

The team proposes a phased remedial strategy and encourages an evaluation of the efficacy of completed efforts to determine whether the remediation should be transitioned from an active to more passive mode. Current federal guidelines for cVOCs (EPA, 1998, EPA 1999) identify three tiers of site-specific lines of evidence to evaluate the efficacy of monitored natural attenuation as a potential corrective measure. These lines of evidence are summarized as follows:

First Line of Evidence: Historical groundwater data that demonstrate a clear and meaningful trend of decreasing contaminant mass and/or concentration over time and distance and the presence of daughter products at appropriate monitoring points. This typically includes graphical techniques using the contaminant monitoring data and statistical tests such as the Mann-Kendall test. At many sites, this line of evidence provides a strong case that attenuation mechanisms are present and allows an assessment of their significance. 
Second Line of Evidence: Hydrogeologic and geochemical data that can be used to demonstrate indirectly the types of natural attenuation processes at the site and the rate at which such processes will reduce contaminant concentrations to required levels. In the initial EPA (1999) protocol, this type of information focused exclusively on conditions that were suited to reductive dechlorination. Example analytes include competing electron acceptors (e.g., oxygen, sulfate, and nitrate), helpful electron donors (e.g., hydrocarbons and hydrogen), and diagnostic indicators and byproducts (e.g., methane and iron). Other destruction mechanisms, such as co-metabolisms, anaerobic and aerobic oxidation, and abiotic degradation are not fully addressed in the typical interpretation of data collected to support the second line of evidence.

Third Line of Evidence: Other information such as data from field or microcosm studies that directly demonstrate or quantify the occurrence of a particular natural attenuation process and ability to degrade contaminants of concern. This type of information has not frequently been collected because of cost and complexity for interpretation.

Since the plume under the building is difficult to characterize and will be difficult to evaluate, plume stability emanating from under the building and downgradient (distal plume) would be the optimal location for evaluation to move to less robust remediation techniques such as monitored natural attenuation.

\section{REMChlor}

REMChlor, or Remediation Evaluation Model for Chlorinated Solvents, is an analytical solution for simulating the transient effects of groundwater source and plume remediation. In the analytical method, the contaminant source model is based on a power-function relationship between source mass and source discharge, and it can consider partial source remediation at any time after the initial release. The source model serves as a time-dependent, mass-flux boundary condition to the analytical plume model, in which flow is assumed to be one dimensional. The plume model simulates first-order sequential decay and production of several species, and the decay rates and parent/daughter yield coefficients are variable functions of time and distance. This approach allows for flexible simulation of enhanced plume degradation that may be temporary, be limited in space, and have different effects on different contaminant species in the decay chain. Health risks posed by carcinogenic species in the plume are calculated with the assumption that the contaminated water is used for domestic consumption (drinking, bathing, and other household activities). 


\subsection{References Cited}

AFCEE (Air Force Center for Environmental Excellence), 2008. Technical Protocol for Enhanced Anaerobic Bioremediation Using Permeable Mulch Biowalls and Bioreactors. Prepared by Parsons Infrastructure \& Technology Group, Inc. under contracts F41624-00-D8024 and F41624-03-D-8613.

DOE, 2006. Building 100 Area Corrective Measures Study Report Addendum. DOELM/GJ1241-2006. July 2006

DOE, 2008a. Interim Remedial Action Plan for Source Removal at the Northeast Site. LMS/PIN/N01221. August 2008

DOE, 2008b. Sitewide Environmental Monitoring Semiannual Progress Report for the YoungRainey STAR Center December 2007 through May 2008. LMS/PIN/N01179. June 2008

DOE, 2009., Sitewide Environmental Monitoring Semiannual Progress Report for the Young Rainey STAR Center June through November 2009). LMS/PIN/N01439. December 2009.

EPA, 1998. Technical Protocol for Evaluation of Natural Attenuation of Chlorinated Solvents in Groundwater, U. S. Environmental Protection Agency.

EPA, 1999. Use of Monitored Natural Attenuation at Superfund, RCRA Corrective Action, and Underground Storage Tank Sites. Washington, D.C., Office of Solid Waste and Emergency Response (OSWER), U. S. Environmental Protection Agency.

Geospatial Environmental Mapping System (GEMS) at the LM website (http://gems.lm.doe.gov/imf/img.jsp?site=pinellascounty\&title=Pinellas County, FL, Site).

Lee, M. D., 2004. TCE plume management through edible oil injection and natural attenuation. Terra Systems Inc.

McCarty, P. L., 2002. Strategies for insitu bioremediation of chlorinated solvent contaminated groundwater. Groundwater Quality: Natural and enhanced restoration of groundwater pollution. S. F. Thornton and S. E. Oswald, International Association of Hydrological Sciences. 275.

Stoller, 2010. Environmental Restoration Activities at the Young-Rainey STAR Center. Presentation to Center for Sustainable Soil and Groundwater Solutions Technical Review Team. April 2010. 